Review

\title{
Prognostic Value of miRNAs in Head and Neck Cancers: A Comprehensive Systematic and Meta-Analysis
}

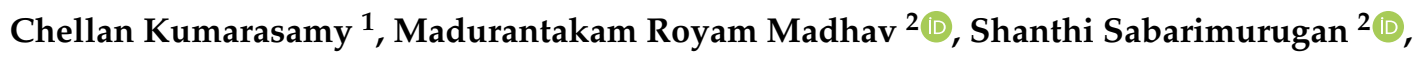 \\ Sunil Krishnan ${ }^{3}$, Siddhartha Baxi ${ }^{4}$, Ajay Gupta ${ }^{5}$, K M Gothandam ${ }^{2}$ and Rama Jayaraj ${ }^{6, *(D)}$ \\ 1 North Terrace Campus, University of Adelaide, Adelaide, South Australia 5005, Australia \\ 2 School of Bio Science and Technology, Vellore Institute of Technology (VIT), Vellore 632014, India \\ 3 Department of Radiation Oncology, Division of Radiation Oncology, The University of Texas MD Anderson \\ Cancer Center, 1515 Holcombe Blvd, Houston, TX 77030, USA \\ 4 John Flynn Private Hospital, Genesis Cancer Care, 42 Inland Drive, Tugun, Queensland 4224, Australia \\ 5 Medical Oncology P-41, South Extension Part 2, New Delhi 110049, India \\ 6 College of Health and Human Sciences, Charles Darwin University, Yellow 1.1.05, Ellengowan Drive, \\ Casuarina, Darwin, Northern Territory 0909, Australia \\ * Correspondence: Rama.Jayaraj@cdu.edu.au; Tel.: +61-0410541300
}

Received: 17 July 2019; Accepted: 18 July 2019; Published: 25 July 2019

\begin{abstract}
Head and Neck Cancer (HNC) is the sixth most common type of cancer across the globe, with more than 300,000 deaths each year, globally. However, there are currently no standardised molecular markers that assist in determining HNC prognosis. The literature for this systematic review and meta-analysis were sourced from multiple bibliographic databases. This review followed PRISMA guidelines. The Hazard Ratio (HR) was selected as the effect size metric to independently assess overall survival (OS), disease-free survival (DFS), and prognosis. Subgroup analysis was performed for individual highly represented miRNA. A total of 6843 patients across 50 studies were included in the systematic review and 34 studies were included in the meta-analysis. Studies across 12 countries were assessed, with China representing $36.7 \%$ of all included studies. The analysis of the survival endpoints of OS and DFS were conducted separately, with the overall pooled effect size (HR) for each being 1.825 (95\% CI 1.527-2.181; $p<0.05$ ) and 2.596 (95\% CI 1.917-3.515; $p<0.05$ ), respectively. Subgroup analysis was conducted for impact of miR-21, 200b, 155, 18a, 34c-5p, 125b, 20a and 375 on OS, and miR-21 and 34a on DFS. The pooled results were found to be statistically significant for both OS and DFS. The meta-analysis indicated that miRNA alterations can account for an $82.5 \%$ decrease in OS probability and a $159.6 \%$ decrease in DFS probability. These results indicate that miRNAs have potential clinical value as prognostic biomarkers in HNC, with miR-21, 125b, $34 c-5 p$ and $18 a$, in particular, showing great potential as prognostic molecular markers. Further large scale cohort studies focusing on these miRNAs are recommended to verify the clinical utility of these markers individually and/or in combination.
\end{abstract}

Keywords: microRNAs; head and neck cancer; prognosis; systematic review; meta-analysis

\section{Introduction}

Head and Neck Cancer (HNC) is the sixth leading cancer by incidence worldwide, with an annual incidence rate of more than 550,000 cases and around 300,000 deaths each year [1]. It has shown to be strongly associated with environmental and lifestyle risk factors including tobacco use, alcohol consumption, human papilloma virus or Ebstein-Barr virus infection, poor oral and dental hygiene, malnutrition, gastroesophageal or laryngopharyngeal reflux disease, and occupational 
exposure to chemicals and fumes [2]. Treatment for early HNC primarily involves multi-modality therapy with a combination of surgery and radiation [3]. Patients with advanced disease stages have been shown to frequently develop recurrences or distant metastases, resulting in five-year overall survival (OS) rates of less than $60 \%$ with poor long-term prognosis [4]. Patients with loco-regional relapse or metastatic disease usually cannot be cured, with only limited benefits arising from palliative chemotherapy [5]. In this regard, there is an urgent need for the identification of biomarkers for accurate prognosis, in order to inform and direct patient treatment. MicroRNAs (miRNAs) have been proposed as quantitative prognostic markers in HNC [6]. MicroRNAs are small non-coding RNAs ( 22 nucleotides) transcribed from DNA into RNA hairpins. MicroRNAs post-transcriptionally regulate gene expression by binding to the $3^{\prime}$-UTR of target mRNAs, resulting in target mRNA degradation or inhibition of their translation $[7,8]$. Other recent studies have also suggested that the secondary structure of the $5^{\prime}$ untranslated region (5' UTR) of messenger RNA (mRNA) is important for microRNA (miRNA)-mediated gene regulation in humans [9]. MiRNAs are first transcribed as primary transcripts (pri-miRNA) with a cap and poly-A tail by RNA polymerase II or RNA polymerase III, with a typical pri-miRNA being composed of a double stranded stem of ' 33 base pairs, a terminal 'hairpin' loop and two flanking unstructured single-stranded segments. MiRNAs are first transcribed as primary transcripts (pri-miRNA) with a cap and poly-A tail by RNA polymerase II or RNA polymerase III, with a typical pri-miRNA being composed of a double stranded stem of '33 base pairs, a terminal 'hairpin' loop and two flanking unstructured single-stranded segments. The Pri-miRNA is then processed to a short 70 nucleotide stem-loop structure known as pre-miRNA by a protein complex known as the Microprocessor complex. After the pre-miRNA is generated in the nucleus, it is exported to the cytoplasm by the action of RanGTPase. In the cytoplasm, an RNAse III endonuclease cleaves pre-miRNA into short miRNA duplexes. After cleavage, the miRNA duplec is unwound by an RNA helicase and the mature miRNA strand binds to an Argonaute (Ago) protein into an RNP complex. The mature miRNA binds to the target mRNA and typically in the $3^{\prime}$-untranslated region ( 3 '-UTR), interfering with the translation of the mRNA, thereby, regulating gene expression in cancer by inhibiting translation or by targeting the mRNA for degradation or deadenylation or by upregulating the translation of oncogenes $[10,11]$. Therefore, MicroRNAs are involved in a variety of biological functions including playing a role in the majority of known hallmarks of cancer, while playing a major role in cancers by functioning as upregulators of oncogenes, or even as tumour suppressors [7]. Furthermore, studies have suggested that due to this, miRNAs have a prognostic value in several human cancers [6,12]. miRNAs can function as both tumour-suppressors as well as oncogenes. Therefore, miRNAs may be capable of offering a sensitive method for HNC detection, monitoring and prognosis. Previous studies have shown that miRNA deregulation occurs in HNC patients. However concrete miRNA prognostic markers capable of informing clinical decision making, have not yet been identified [13]. Therefore, an objective, systematic review on studies about miRNA and HNC was performed, in order to elucidate the significance of specific miRNA in HNC prognosis. Additionally, a comprehensive meta-analysis was performed to investigate the significance of miRNA in determining patient prognosis, with subsequent subgroup analysis further exploring the prognostic significance of frequently expressed miRNAs.

\section{Methods}

\subsection{Search Strategy and Study Selection}

The following systematic review and meta-analysis were conducted based on the Preferred Reporting Items for Systematic reviews and Meta-Analysis (PRISMA) guidelines [14]. The search strategy was designed to be comprehensive and exhaustive with a prime focus on minimising bias and maximising sensitivity. The EMBASE, PubMed, Web of Science and Science Direct bibliographic databases were used to search for relevant published literature in the field of miRNA as prognostic 
markers in HNC. Predefined 'search strings' (as shown in Supplementary Table S1) were generated using a few core 'keywords', which included;

miRNA

Head and Neck Cancer

Prognosis

Survival

Overall Survival

Disease-Free Survival

miRNA expression

upregulation

downregulation

deregulation/dysregulation

Biomarkers

Treatment

Surgical resection

Radiotherapy

Chemotherapy

Clinical study

Oral cancer

Head and Neck Squamous Cell Carcinoma (HNSCC)

These 'search strings' were subsequently used for searching literature databases for relevant studies published until September 2018. The search was conducted individually by two reviewers (C.K. and R.J.), in order to ameliorate any possible selection bias. Initial screening of articles and studies was based on the pertinence of the title and abstract of each publication to the systematic review and meta-analysis. The screening was conducted simultaneously alongside the initial search, at the discretion of the two reviewers (C.K. and R.J.). To further bolster the results of the search strategy, the reference lists of included publications (initial post-screening), were also screened for pertinent studies. Any disagreements arising during initial screening were solved with the inclusion of the third reviewer.

\subsection{Inclusion and Exclusion Criteria}

After initial search and screening, the full-texts of selected studies were then subjected to further rigorous screening based on a set of predefined inclusion and exclusion criteria. This secondary screening process was also conducted by two reviewers in tandem (C.K. and R.J.), based on the following criteria:

Inclusion criteria

The studies discuss miRNA expression in HNC patients.

The studies investigate the association between miRNA expression and patient survival in HNC.

The studies explicitly presented the resulting survival data in terms of hazard ratios (HRs) and 95\% confidence intervals (CIs). or both.

The studies assessed patient survival based on the endpoints of OS, disease-free survival (DFS),

The studies provided sufficient data to extract the $\mathrm{HR}$ and $95 \% \mathrm{CI}$, in case the studies do not explicitly state these values.

Exclusion criteria

Conference abstracts, reviews and correspondence.

Studies that only reported results from in-vitro, in-silico or animal studies.

Studies that were conducted as part of theses, or incomplete studies.

Studies will very small sample sizes, or case studies. 
No limits were placed on the patients' demographic or the clinicopathological characteristics, for the selection of studies for conducting the systematic review and meta-analysis.

\subsection{Data Extraction}

Extraction of data from selected studies was preceded by the preparation of a standardised data extraction form using Microsoft Excel. The data extraction was carried out individually, with all collated data bring combined into one single database at the end of the extraction process, with duplicated data being simultaneously removed. All tables, charts and figures from selected studies were compiled into a separate database for ease of analysis. The following data items were extracted from the studies:

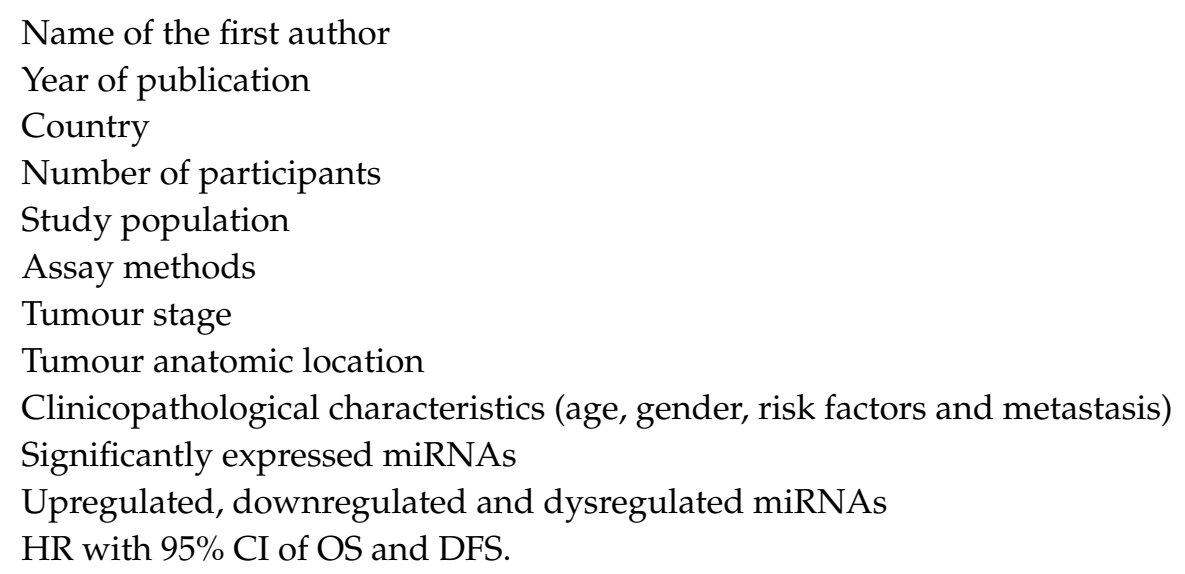

\subsection{Quality Assessment}

The quality of included studies was based on a quality assessment tool developed by the National Heart, Lung and Blood Institute (NHLBI) (USA) for Observational and Cross-sectional studies [15]. This tool was applied to the full texts of all included studies. The NHLBI quality assessment tool uses a set of 14 criteria according to which each study is subjectively rated as 'good', 'fair', or 'poor' based on the opinion of two reviewers. As per the guidelines accompanying the assessment tool, the quality assessment was carried out independently by the reviewers. A 'high' quality rating via this tool corresponds to a low risk of bias in the study being assessed, while a 'low' quality rating is indicative of a high risk of bias.

\subsection{Meta-Analysis and Assessment of Heterogeneity}

The meta-analysis was conducted using the aid of the Comprehensive Meta-Analysis software [16]. The HR and 95\% CI values for OS and DFS extracted from each study were pooled together in the form of a Forest Plot. As HR is the effect size metric chosen for the study, the pooled HR and 95\% $\mathrm{CI}$ are indicative of the probability of survival for given miRNA expression, thereby indicating the prognostic value of said miRNA. The random-effects model of the meta-analysis was chosen to pool the HR values, due to the inherent heterogeneity that arises from the differences between the study parameters of each study [17]. In the case of studies not presenting the HR and 95\% CI values for OS and DFS, the respective values were estimated using the Kaplan-Meier curves for miRNA expression, which were presented in said studies. Additionally, for the assessment and comparison of miRNA concerning each other, each assessment of a discrete patient group within the larger patient group of a single study will be included in the meta-analysis as a unique cohort. Subgroup analysis was carried out based on the survival endpoint of each study (OS or DFS), the change in the miRNA expression (upregulated/downregulated), and the specific miRNA that was represented in at least two separate studies.

The assessment of between-study heterogeneity was based on the Higgins $I^{2}$ statistic, Cochran's $Q$ and the $\mathrm{Tau}^{2}$ value [18-20]. The $\mathrm{I}^{2}$ statistic was the primary method of assessing heterogeneity, owing 
to its high power of detection (a lower $\mathrm{I}^{2}$ value indicates a lower amount of heterogeneity). However, as $\mathrm{I}^{2}$ may generate biased results in a small meta-analysis, the Cochran's $Q$ Test and Tau ${ }^{2}$ value were also assessed in order to generate a higher degree redundancy in the assessment of heterogeneity between studies [21]. Here, the Tau ${ }^{2}$ value refers to the variance of effect size parameters across the population of studies and reflects the variance of true effect sizes.

\subsection{Publication Bias}

Publication bias is inherent to studies such as systematic reviews and meta-analyses as they consist of previously published studies and literature [22-27]. This bias is an extension of the publication process wherein it is more likely that extensive studies and positive results are published, while smaller studies and negative results are unfavoured and often are not published as part of the peer-reviewed literature $[23,24,28-31]$. Therefore, publication bias cannot be wholly eradicated from any systematic review and meta-analysis study $[32,33]$. To ameliorate this issue, assessment of publication bias was conducted to assess the degree of impact publication bias has upon this study's results [30,34-36].

The Egger's graphical test for assessment of bias was used to construct a funnel plot (a scatter plot constructed using the standard error [ $y$-axis $]$ and $\log$ (HR) $[x$-axis $]$ ), of all included studies. The symmetry of the study distribution on the plot, across the regression line, is inversely correlated with the magnitude of publication bias in the meta-analysis [37].

The Orwin's Fail-Safe N test was used to determine the presence of missing studies that may skew the regression line in the funnel plot, with Duval and Tweedie's Trim and Fill method being used for imputation of the missing studies [38,39]. These methods were used in conjunction to adjust the Funnel Plot to better represent the likely publication bias.

Additionally, the Begg and Mazumdar's Rank Correlation test was used to correlate the ranks of effect sizes and the ranks of their variances, with a positive value indicating a higher test accuracy [40].

\section{Results}

\subsection{Study Selection and Data Extraction}

After following the search strategy, the number of search results of all databases combined totalled to 30,612 potential studies. Out of these studies, a majority were screened out by the reviewers, as they were not relevant to the study being conducted or were focused on tangential topics of research. After this initial screening, 152 studies were selected for further processing. Eliminating duplicates in the search results led to further 22 studies being eliminated, leaving 130 studies for secondary screening based on the inclusion and exclusion criteria. The full texts of the 130 studies were obtained and screened, leading to 99 studies being eliminated and leaving a final total of 31 studies for conducting the study. Screening of the reference lists of these 31 studies revealed 19 more studies that satisfied the requirements for being included in this systematic review and meta-analysis. A final total of 50 studies were included for the systematic review part of the study. However, as not all 50 studies presented sufficient statistical data for conducting of a meta-analysis, studies that did not present $\mathrm{HR}$ and $95 \% \mathrm{CI}$ values, and did not have data from which these values could be extracted, were eliminated from the meta-analysis. Therefore, 16 studies were eliminated, and a total of 34 studies were included in the meta-analysis. The entire process was monitored by the third reviewer at all stages. Figure 1 depicts the entire study selection process in the form of a flowchart. 


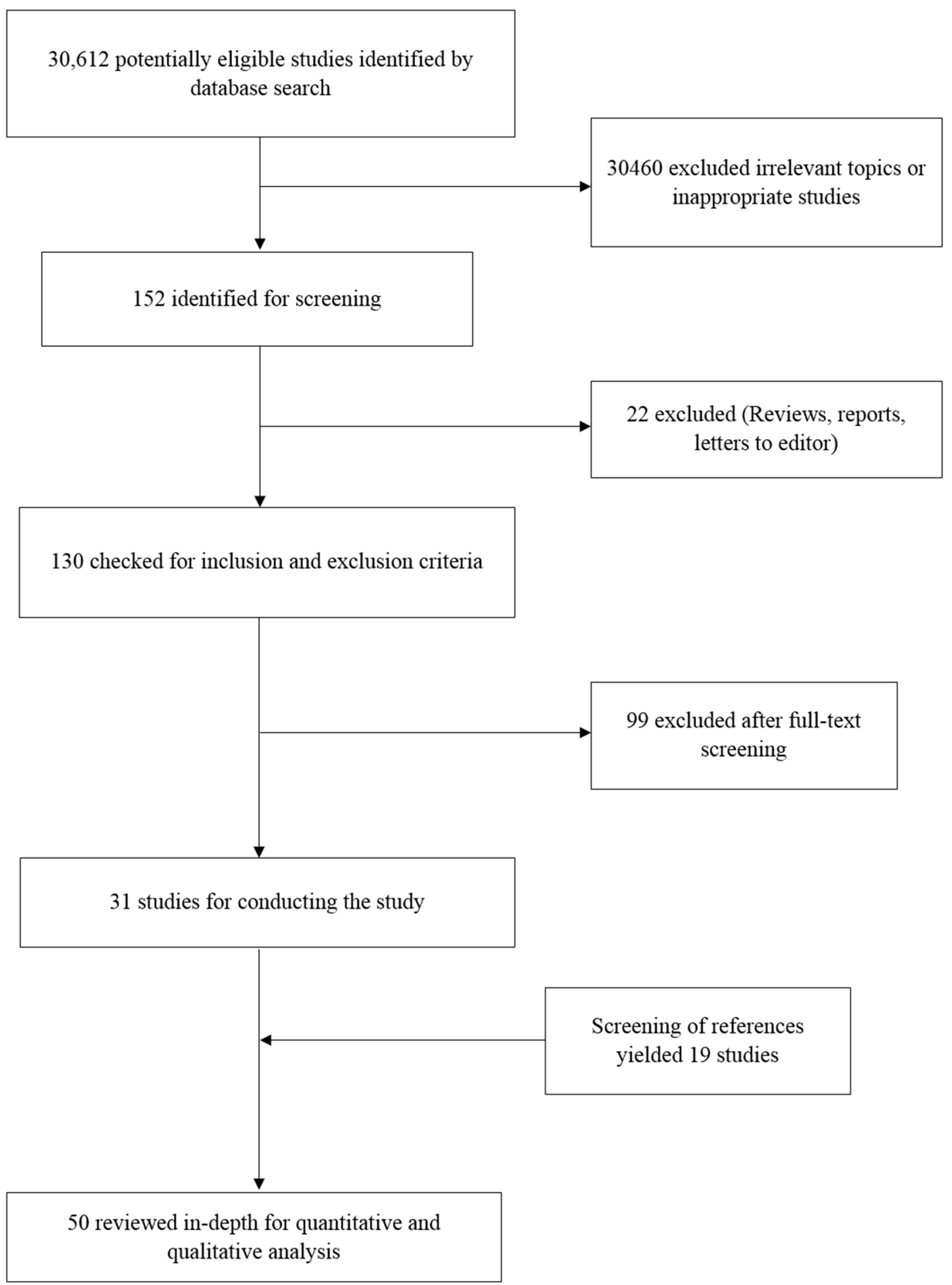

Figure 1. Flow chart describing search strategy. 


\subsection{Study Characteristics}

The 50 studies included in this systematic review and meta-analysis study were found to originate from 12 countries around the world, including Brazil $(n=3)$, Canada $(n=2)$, China $(n=18)$, Chile $(n=1)$, Czech Republic $(n=1)$, Denmark $(n=1)$, Germany $(n=2)$, Italy $(n=3)$, Japan $(n=5)$, Taiwan $(n=6)$, UK $(n=2)$ and USA $(n=5)$, while one study did not specify the region in which it was conducted. A total of 6834 patients across the 50 studies were included in this study. Out of all 50 studies, 39 studies were found to involve a higher percentage of men compared to women, with only 1 study reporting having women as the majority of its participants, while the remaining ten studies did not divulge any information regarding the gender ratios of their participants. The miRNA expression in patients was detected using qRT-PCR in 44 studies and immunohistochemistry in 3 studies, with the rest of the studies using other different techniques. In-situ hybridisation (ISH) was also used by three studies, in conjunction with qRT-PCR as the primary method of miRNA quantification. Patients included in 14 of the studies were also found to indulge, or were formerly indulging in smoking, with the studies showing that smokers formed the majority of the at-risk group of these studies, with only three studies describing risk factors besides smoking. The rest of the 33 studies did not provide any information regarding risk factors in the given patient groups. The study and patient characteristics of all 50 studies are described in Table 1.

\subsection{Meta-Analysis}

The primary meta-analysis studied the prognostic significance of 44 miRNA across 34 studies. The meta-analysis was conducted in 2 parts, based on the survival endpoint used by each study. The meta-analysis pooling the HR and $95 \%$ CIs of studies that used OS as their endpoint $(n=34)$, gave an overall effect size estimate (HR) of 1.825 (95\% CI 1.527-2.181), while the pooled effect size estimate (HR) for studies using DFS as their survival endpoint was 2.596 (95\% CI 1.917-3.514). The pooled effect estimate of OS studies $(p<0.05)$ as well as that of DFS studies $(p<0.05)$ were found to be statistically significant, thereby rejecting the null hypothesis. This indicates that any change in miRNA expression (either overexpressed or underexpressed) compared to controls, leads to a lower probability of survival in HNC patients. Additionally the between-study heterogeneity was found to be high, $\left(\mathrm{I}^{2}=75.055\right.$; $\mathrm{Tau}^{2}=0.228$; Cochran's $Q=176.38$ for OS meta-analysis and $\mathrm{I}^{2}=43.729$; $\mathrm{Tau}^{2}=0.155$; Cochran's $Q=23.103$ for DFS). The forest plots of OS and DFS are presented in Figures 2 and 3, respectively.

\subsection{Subgroup Analysis}

\subsubsection{Upregulation and Downregulation Subgroups}

Subgroups were formed based on whether the miRNAs assessed in each study was found to be upregulated or downregulated compared to controls. The subgroups for upregulated and downregulated miRNA were assessed separately for OS and DFS.

For OS, the upregulated miRNA cohorts $(n=25)$ showed a pooled effect estimate (HR) of 1.762 (95\% CI 1.432-2.168; $p<0.05)$, while the downregulated miRNA $(n=20)$ cohorts showed a pooled effect estimate (HR) of 2.018 (95\% CI 1.431-2.168; $p<0.05)$. The results were also found to be statistically significant for both upregulation and downregulation. 
Table 1. The study and patient characteristics of all 50 studies.

\begin{tabular}{|c|c|c|c|c|c|c|c|c|c|c|c|}
\hline Article & Year & $\operatorname{miR}$ & $\begin{array}{l}\text { Sample } \\
\text { Size }\end{array}$ & Anatomic Location & Assay Method & $\begin{array}{c}\text { Study } \\
\text { Population }\end{array}$ & Gender & Stage & Metastasis & $\begin{array}{c}\text { Risk } \\
\text { Factors }\end{array}$ & Age \\
\hline $\begin{array}{l}\text { Carvalho } \\
\text { et al. [41] }\end{array}$ & 2015 & $\begin{array}{l}\text { miR-203 } \\
\text { miR-205 }\end{array}$ & 127 & $\begin{array}{c}\text { Tongue } 58.3 \% \\
\text { Floor of mouth } 31.3 \% \\
\text { Alveolar ridge } 8.3 \% \\
\text { Lower gum } 2.1 \%\end{array}$ & qRT-PCR & Brazil & $\begin{array}{c}\text { Male } \\
(79.2 \%)\end{array}$ & $\mathrm{T} 2(62.5 \%)$ & $\begin{array}{c}\text { Metastases + ve } \\
(52.083 \%) \\
\text { Metastases - ve } \\
(47.916 \%)\end{array}$ & $\begin{array}{c}\text { Smoking } \\
(47.9 \%)\end{array}$ & $43-84$ \\
\hline $\begin{array}{c}\text { Hou et.al. } \\
\text { [42] }\end{array}$ & 2015 & $\begin{array}{c}\operatorname{miR}-223 \\
\text { miR-99a } \\
\text { miR-21 }\end{array}$ & 16 & Head and Neck & qRT-PCR & Japan & $\begin{array}{c}\text { Male } \\
(93.75 \%)\end{array}$ & $\begin{array}{c}\text { T2 }(18.75 \%) \\
\text { T3 }(12.5 \%) \\
\text { T4 }(68.75 \%)\end{array}$ & NA & NA & $48-80$ \\
\hline $\begin{array}{c}\text { Maia et al. } \\
\text { [43] }\end{array}$ & 2015 & miR-296-5p & 34 & $\begin{array}{l}\text { Supraglottic } 20.6 \% \\
\text { Glottic } 79.4 \%\end{array}$ & qRT-PCR & Brazil & $\begin{array}{c}\text { Male } \\
(88.2 \%)\end{array}$ & $\begin{array}{l}\text { T1 }(47.1 \%) \\
\text { T2 }(52.9 \%)\end{array}$ & NA & $\begin{array}{l}\text { Tobacco } \\
(91.2 \%)\end{array}$ & $\begin{array}{c}\leq 60 \text { years } \\
(47 \%) \\
>60 \text { years } \\
(53 \%)\end{array}$ \\
\hline $\begin{array}{l}\text { Hudcova } \\
\text { et al. [44] }\end{array}$ & 2016 & $\begin{array}{c}\text { miR-29c } \\
\text { miR-200b } \\
\text { miR-375 }\end{array}$ & 42 & Head and Neck & qRT-PCR & $\begin{array}{l}\text { Czech } \\
\text { Republic }\end{array}$ & $\begin{array}{l}\text { Male } \\
(100 \%)\end{array}$ & $\begin{array}{c}\mathrm{T} 1+\mathrm{T} 2 \\
(45 \%) \\
\mathrm{T} 3+\mathrm{T} 4 \\
(55 \%)\end{array}$ & $\begin{array}{c}\text { Metastases + ve } \\
(11.42 \%) \\
\text { Metastases - ve } \\
(88.57 \%)\end{array}$ & NA & NA \\
\hline $\begin{array}{l}\text { Wang et al. } \\
\text { [45] }\end{array}$ & 2015 & $\operatorname{miR}-451$ & 50 & Head and Neck & qRT-PCR & China & NA & NA & NA & NA & NA \\
\hline $\begin{array}{c}\text { Arantes et al. } \\
{[46]}\end{array}$ & 2017 & $\mathrm{miR}-21$ & 71 & $\begin{array}{c}\text { Oropharynx } 49.3 \% \\
\text { Larynx } 39.4 \% \\
\text { Hypopharynx } 11.3 \%\end{array}$ & qRT-PCR & Brazil & $\begin{array}{c}\text { Male } \\
(95.8 \%)\end{array}$ & $\begin{array}{c}\mathrm{T} 2+\mathrm{T} 3 \\
(64.8 \%) \\
\mathrm{T} 4(35.2 \%)\end{array}$ & NA & $\begin{array}{c}\text { HPV } \\
(8.45 \%) \\
\text { Tobacco } \\
(80.3 \%) \\
\text { Alcohol } \\
(38.0 \%)\end{array}$ & $40-76$ \\
\hline Xu et al. [47] & 2015 & miR-483-5p & 101 & Oral Cavity & qRT-PCR & China & $\begin{array}{c}\text { Male } \\
(76.2 \%)\end{array}$ & $\begin{array}{l}\mathrm{T} 1+\mathrm{T} 2 \\
(50.5 \%) \\
\mathrm{T} 3+\mathrm{T} 4 \\
(49.5 \%)\end{array}$ & NA & $\begin{array}{c}\text { Smoking } \\
(72.3 \%) \\
\text { Alcohol } \\
(68.3 \%)\end{array}$ & $53.2 \pm 10.3$ \\
\hline Li et al. [48] & 2015 & miR-93 & 103 & $\begin{array}{c}\text { Supraglottic } 25.24 \% \\
\text { Glottic } 55.33 \% \\
\text { Hypopharynx } 9.7 \% \\
\text { Oral Cavity } 9.7 \%\end{array}$ & ISH, qRT-PCR & China & $\begin{array}{c}\text { Male } \\
(96.1 \%)\end{array}$ & $\begin{array}{c}\text { T1 }(15.5 \%) \\
\text { T2 }(35 \%) \\
\text { T3 }(40.8 \%) \\
\text { T4 }(8.7 \%)\end{array}$ & $\begin{array}{c}\text { Metastases + ve } \\
(38.83 \%)\end{array}$ & NA & $\begin{array}{l}<58(46 \%) \\
\geq 58(54 \%)\end{array}$ \\
\hline Hu et al. [49] & 2014 & $\begin{array}{l}\operatorname{miR}-21 \\
\text { miR-375 }\end{array}$ & 46 & $\begin{array}{c}\text { Glottic } 71.7 \% \\
\text { Supraglottic } 23.9 \% \\
\text { Subglottic } 4.4 \%\end{array}$ & qRT-PCR & China & $\begin{array}{c}\text { Male } \\
(91.3 \%)\end{array}$ & $\begin{array}{c}\mathrm{T} 0+\mathrm{T} 1+ \\
\mathrm{T} 2(45.7 \%) \\
\mathrm{T} 3+\mathrm{T} 4 \\
(54.3 \%)\end{array}$ & NA & $\begin{array}{c}\text { Smoking } \\
(72.1 \%) \\
\text { Alcohol } \\
(46.3 \%)\end{array}$ & $59.2 \pm 7.84$ \\
\hline
\end{tabular}


Table 1. Cont.

\begin{tabular}{|c|c|c|c|c|c|c|c|c|c|c|c|}
\hline Article & Year & $\operatorname{miR}$ & $\begin{array}{l}\text { Sample } \\
\text { Size }\end{array}$ & Anatomic Location & Assay Method & $\begin{array}{c}\text { Study } \\
\text { Population }\end{array}$ & Gender & Stage & Metastasis & $\begin{array}{c}\text { Risk } \\
\text { Factors }\end{array}$ & Age \\
\hline $\begin{array}{l}\text { Hedback } \\
\text { et al. [50] }\end{array}$ & 2014 & miR-21 & 86 & Oral Cavity & $\begin{array}{c}\text { ISH, } \\
\text { Immunohistochemistry }\end{array}$ & Denmark & NA & NA & NA & NA & NA \\
\hline $\begin{array}{c}\text { Sun et al. } \\
\text { [51] }\end{array}$ & 2015 & miR-320a & 450 & Salivary Gland & $\begin{array}{c}\text { ISH, } \\
\text { Immunohistochemistry }\end{array}$ & China & $\begin{array}{c}\text { Male } \\
(47.56 \%)\end{array}$ & $\begin{array}{c}\mathrm{T} 1+\mathrm{T} 2 \\
(65.33 \%) \\
\mathrm{T} 3+\mathrm{T} 4 \\
(34.67 \%)\end{array}$ & $\begin{array}{c}\text { Metastases + ve } \\
(43.56 \%)\end{array}$ & NA & $\begin{array}{l}<50(49 \%) \\
\geq 50(51 \%)\end{array}$ \\
\hline $\begin{array}{l}\text { Saito et al. } \\
\text { [52] }\end{array}$ & 2013 & miR-196a & 84 & Larynx & qRT-PCR & Japan & NA & NA & NA & NA & NA \\
\hline Li et al. [53] & 2009 & miR-21 & 103 & Tongue & qRT-PCR & China & $\begin{array}{c}\text { Male } \\
(54.36 \%)\end{array}$ & $\begin{array}{c}\mathrm{T} 1+\mathrm{T} 2 \\
(58.25 \%) \\
\mathrm{T} 3+\mathrm{T} 4 \\
(41.75 \%)\end{array}$ & $\begin{array}{c}\text { Metastases + ve } \\
(27.18 \%)\end{array}$ & NA & $\begin{array}{l}<50(46 \% \\
\geq 50(54 \%)\end{array}$ \\
\hline Liu et al. [54] & 2012 & $\begin{array}{c}\text { miR-93 } \\
\text { miR-142-3p } \\
\text { miR-29c } \\
\text { miR-26a } \\
\text { miR-30e }\end{array}$ & 465 & Nasopharyngeal & qRT-PCR & China & $\begin{array}{c}\text { Male } \\
(74.19 \%)\end{array}$ & $\begin{array}{l}\text { T1 }(21.94 \%) \\
\text { T2 }(27.31 \%) \\
\text { T3 }(23.66 \%) \\
\text { T4 }(27.10 \%)\end{array}$ & $\begin{array}{c}\text { Metastases + ve } \\
(19.78 \%))\end{array}$ & NA & $47.09 \pm 11$ \\
\hline $\begin{array}{l}\text { Summerer } \\
\text { et al. [55] }\end{array}$ & 2013 & $\begin{array}{c}\text { miR-425-5p } \\
\text { miR-21-5p } \\
\text { miR-106b-5p } \\
\text { miR-93-5p }\end{array}$ & 18 & $\begin{array}{c}\text { Larynx } 27.77 \% \\
\text { Oropharynx } 16.66 \% \\
\text { Mouth floor } 11.11 \% \\
\text { Tongue } 11.11 \% \\
\text { Esophagus 5.55\% } \\
\text { Hypopharynx 5.55\% } \\
\text { Maxilla } 5.55 \% \\
\text { Nasopharyngeal 5.55\% } \\
\text { Sinuses 5.55\% } \\
\text { Soft palate 5.55\% } \\
\end{array}$ & qRT-PCR & Germany & $\begin{array}{c}\text { Male } \\
(77.78 \%)\end{array}$ & $\begin{array}{l}\text { T1 }(22.22 \%) \\
\text { T2 }(11.11 \%) \\
\text { T3 }(33.33 \%) \\
\text { T4 }(33.33 \%)\end{array}$ & $\begin{array}{c}\text { Metastases + ve } \\
(11.11 \%)\end{array}$ & NA & $45.1-80.6$ \\
\hline $\begin{array}{c}\text { Suh et al. } \\
\text { [56] }\end{array}$ & 2015 & miR-196a & 16 & Oral Cavity & qRT-PCR & UK & NA & NA & NA & NA & NA \\
\hline $\begin{array}{c}\text { Ogawa et al. } \\
\text { [57] }\end{array}$ & 2012 & miR-34a & 24 & Sinonasal & miRNA-Microarray & Japan & $\begin{array}{c}\text { Male } \\
(66.67 \%)\end{array}$ & $\begin{array}{c}\text { T2 (4\%) } \\
\text { T3 (41.67\%) } \\
\text { T4 }(54.17 \%)\end{array}$ & $\begin{array}{c}\text { Metastases + ve } \\
(8.33 \%)\end{array}$ & NA & $\begin{array}{l}>60(59 \%) \\
<60(41 \%)\end{array}$ \\
\hline
\end{tabular}


Table 1. Cont.

\begin{tabular}{|c|c|c|c|c|c|c|c|c|c|c|c|}
\hline Article & Year & $\operatorname{miR}$ & $\begin{array}{l}\text { Sample } \\
\text { Size }\end{array}$ & Anatomic Location & Assay Method & $\begin{array}{c}\text { Study } \\
\text { Population }\end{array}$ & Gender & Stage & Metastasis & $\begin{array}{c}\text { Risk } \\
\text { Factors }\end{array}$ & Age \\
\hline $\begin{array}{c}\text { Avissar et al. } \\
\text { [58] }\end{array}$ & 2009 & $\begin{array}{c}\operatorname{miR}-375 \\
\operatorname{miR}-21\end{array}$ & 169 & $\begin{array}{c}\text { Oral } 64 \% \\
\text { Pharynx } 21 \% \\
\text { Larynx } 15 \%\end{array}$ & qRT-PCR & USA & Male $(68 \%)$ & $\begin{array}{c}\mathrm{T} 1+\mathrm{T} 2 \\
(28 \%) \\
\mathrm{T} 3+\mathrm{T} 4 \\
(72 \%)\end{array}$ & NA & $\begin{array}{c}\text { HPV } \\
(17.4 \%) \\
\text { Alcohol } \\
(88.5 \%) \\
\text { Smoking } \\
(84.5 \%)\end{array}$ & $61.5 \pm 11.9$ \\
\hline $\begin{array}{l}\text { Massimo Re } \\
\text { et al. [59] }\end{array}$ & 2015 & $\operatorname{miR}-34 c-5 p$ & 90 & $\begin{array}{c}\text { Supraglottic } 21.1 \% \\
\text { Transglottic } 73.3 \% \\
\text { Subglottic 5.6\% }\end{array}$ & qRT-PCR & Italy & $\begin{array}{l}\text { Male } \\
(96.6 \%)\end{array}$ & $\begin{array}{l}\text { T3 }(66.7 \%) \\
\text { T4 }(33.3 \%)\end{array}$ & $\begin{array}{c}\text { Metastases + ve } \\
(0 \%)\end{array}$ & NA & $66.51 \pm 8.02$ \\
\hline $\begin{array}{l}\text { Sun et al. } \\
\text { [60] }\end{array}$ & 2013 & miR-363 & 62 & $\begin{array}{c}\text { Tongue } 41.9 \% \\
\text { Gingival } 21 \% \\
\text { Cheek } 11.3 \% \\
\text { Floor of Mouth } 17.7 \% \\
\text { Oropharynx } 8.1 \%\end{array}$ & qRT-PCR & China & $\begin{array}{l}\text { Male } \\
(69.4 \%)\end{array}$ & $\begin{array}{l}\mathrm{T} 1+\mathrm{T} 2 \\
(43.5 \%) \\
\mathrm{T} 3+\mathrm{T} 4 \\
(36.5 \%)\end{array}$ & $\begin{array}{c}\text { Metastases + ve } \\
(54.83 \%)\end{array}$ & $\begin{array}{c}\text { Smoking } \\
(48.4 \%) \\
\text { Drinking } \\
(32.3 \%)\end{array}$ & $\begin{array}{l}\geq 60(42 \%) \\
<60(58 \%)\end{array}$ \\
\hline $\begin{array}{c}\text { Tian et al. } \\
\text { [61] }\end{array}$ & 2014 & miR-203 & 56 & $\begin{array}{c}\text { Glottic 53.57\% } \\
\text { Supraglottic } 46.43 \%\end{array}$ & qRT-PCR & China & $\begin{array}{c}\text { Male } \\
(71.43 \%)\end{array}$ & $\begin{array}{c}\mathrm{T} 1+\mathrm{T} 2 \\
(42.85 \%) \\
\mathrm{T} 3+\mathrm{T} 4 \\
(57.14 \%)\end{array}$ & $\begin{array}{c}\text { Metastases + ve } \\
(50 \%)\end{array}$ & NA & $\begin{array}{l}\geq 59(57 \%) \\
<59(43 \%)\end{array}$ \\
\hline $\begin{array}{l}\text { Chang et al. } \\
\text { [62] }\end{array}$ & 2013 & $\begin{array}{l}\mathrm{miR}-17 \\
\mathrm{miR}-20 \mathrm{a}\end{array}$ & 98 & $\begin{array}{c}\text { Buccal Mucosa } 43.88 \% \\
\text { Tongue } 29.59 \% \\
\text { Gingiva } 21.43 \% \\
\text { Floor of Mouth } 5.10 \%\end{array}$ & qRT-PCR & Taiwan & $\begin{array}{l}\text { Male } \\
(84.7 \%)\end{array}$ & $\begin{array}{l}\mathrm{T} 1+\mathrm{T} 2 \\
(44.9 \%) \\
\mathrm{T} 3+\mathrm{T} 4 \\
(55.1 \%)\end{array}$ & $\begin{array}{c}\text { Metastases + ve } \\
(37.75 \%)\end{array}$ & $\begin{array}{l}\text { Smoking } \\
(82.65 \%)\end{array}$ & $\begin{array}{l}>50(35 \%) \\
<50(65 \%)\end{array}$ \\
\hline $\begin{array}{c}\text { Gee et al. } \\
\text { [63] }\end{array}$ & 2010 & $\operatorname{miR}-210$ & 46 & $\begin{array}{c}\text { Oral Cavity } 21 \% \\
\text { Oropharynx } 46 \% \\
\text { Hypopharynx } 19 \% \\
\text { Larynx } 11 \% \\
\text { Paranasal Sinus } 2 \%\end{array}$ & qRT-PCR & UK & $\begin{array}{l}\text { Male } \\
(80.43 \%)\end{array}$ & $\begin{array}{l}\text { T1 }(10.87 \%) \\
\text { T2 }(30.43 \%) \\
\text { T3 }(15.22 \%) \\
\text { T4 }(43.48 \%)\end{array}$ & NA & $\begin{array}{l}\text { Smoking } \\
(86.96 \%) \\
\text { Alcohol } \\
(78.26 \%)\end{array}$ & $43-92$ \\
\hline $\begin{array}{l}\text { Lenarduzzi } \\
\text { et al. [64] }\end{array}$ & 2013 & miR-193b & 51 & Head and Neck & qRT-PCR & Canada & NA & NA & NA & NA & NA \\
\hline $\begin{array}{l}\text { Childs et al. } \\
\text { [65] }\end{array}$ & 2009 & $\begin{array}{l}\text { miR-205 } \\
\text { Let-7d } \\
\text { miR-21 }\end{array}$ & 104 & $\begin{array}{c}\text { Oral Cavity } 30 \% \\
\text { Oropharynx } 46 \% \\
\text { Hypopharynx } 9 \% \\
\text { Larynx } 31 \%\end{array}$ & qRT-PCR & US & Male (68\%) & $\begin{array}{c}\mathrm{T} 1+\mathrm{T} 2 \\
(23 \%) \\
\mathrm{T} 3+\mathrm{T} 4 \\
(77 \%)\end{array}$ & NA & $\begin{array}{c}\text { Smoking } \\
(82 \%) \\
\operatorname{HPV}(36 \%)\end{array}$ & $\begin{array}{l}<60(40 \%) \\
>60(61 \%)\end{array}$ \\
\hline
\end{tabular}


Table 1. Cont

\begin{tabular}{|c|c|c|c|c|c|c|c|c|c|c|c|}
\hline Article & Year & $\operatorname{miR}$ & $\begin{array}{l}\text { Sample } \\
\text { Size }\end{array}$ & Anatomic Location & Assay Method & $\begin{array}{c}\text { Study } \\
\text { Population }\end{array}$ & Gender & Stage & Metastasis & $\begin{array}{c}\text { Risk } \\
\text { Factors }\end{array}$ & Age \\
\hline $\begin{array}{c}\text { Shen et al. } \\
\text { [66] }\end{array}$ & 2012 & miR-34a & 69 & Larynx & qRT-PCR & China & NA & $\begin{array}{c}\mathrm{T} 1+\mathrm{T} 2 \\
(60.87 \%) \\
\mathrm{T} 3+\mathrm{T} 4 \\
(39.13 \%)\end{array}$ & $\begin{array}{c}\text { Metastases + ve } \\
(34.78 \%)\end{array}$ & NA & $\begin{array}{l}<60(48 \%) \\
\geq 60(52 \%)\end{array}$ \\
\hline $\begin{array}{l}\text { Luo et al. } \\
\text { [67] }\end{array}$ & 2013 & miR-18a & 168 & Nasopharyngeal & qRT-PCR & China & $\begin{array}{c}\text { Male } \\
(75.6 \%)\end{array}$ & $\begin{array}{c}\mathrm{T} 1+\mathrm{T} 2 \\
(42.86 \%) \\
\mathrm{T} 3+\mathrm{T} 4 \\
(57.14 \%)\end{array}$ & $\begin{array}{c}\text { Metastases + ve } \\
\quad(64.88 \%)\end{array}$ & NA & $\begin{array}{l}\geq 50(59 \%) \\
<50(41 . \%)\end{array}$ \\
\hline $\begin{array}{c}\text { Jung et al. } \\
\text { [68] }\end{array}$ & 2012 & miR-21 & 17 & $\begin{array}{c}\text { Tongue } 94.12 \% \\
\text { Oropharynx } 5.88 \%\end{array}$ & qRT-PCR & USA & NA & NA & NA & $\begin{array}{c}\text { HPV } \\
(58.82 \%)\end{array}$ & $41-69$ \\
\hline $\begin{array}{c}\text { Sasahira et al. } \\
\text { [69] }\end{array}$ & 2012 & miR-126a & 118 & $\begin{array}{l}\text { Tongue } 54.24 \% \\
\text { Other } 45.76 \%\end{array}$ & qRT-PCR & Japan & $\begin{array}{c}\text { Male } \\
(57.63 \%)\end{array}$ & $\begin{array}{c}\mathrm{T} 1+\mathrm{T} 2 \\
(76.27 \%) \\
\mathrm{T} 3+\mathrm{T} 4 \\
(23.73 \%)\end{array}$ & $\begin{array}{l}\text { Metastases + ve } \\
\quad(28.81 \%)\end{array}$ & NA & $\begin{array}{l}\leq 65(39 \%) \\
>65(61 \%)\end{array}$ \\
\hline Liu et al. [70] & 2014 & miR-134a & 96 & $\begin{array}{c}\text { Buccal Mucosa } 35.41 \% \\
\text { Tongue } 27.08 \% \\
\text { Oral pharynx } 37.5 \%\end{array}$ & qRT-PCR & Taiwan & $\begin{array}{c}\text { Male } \\
(93.75 \%)\end{array}$ & $\begin{array}{c}\mathrm{T} 1+\mathrm{T} 2+ \\
\mathrm{T} 3(28.12 \%) \\
\mathrm{T} 4(71.88 \%)\end{array}$ & $\begin{array}{c}\text { Metastases + ve } \\
(6.25 \%)\end{array}$ & NA & 53.5 (Average) \\
\hline Shi et al. [71] & 2014 & miR-155 & 30 & Oral Cavity & qRT-PCR, FISH & China & $\begin{array}{c}\text { Male } \\
(63.33 \%)\end{array}$ & $\begin{array}{c}\text { T1 (10\%) } \\
\text { T2 (16.67\%) } \\
\text { T3 }(33.33 \%) \\
\text { T4 }(40 \%)\end{array}$ & NA & $\begin{array}{c}\text { Smoking } \\
(46.67 \%) \\
\text { Alcohol } \\
(53.33 \%)\end{array}$ & $\begin{array}{c}56.4 \pm 8.6 \\
(40-75)\end{array}$ \\
\hline $\begin{array}{l}\text { Harris et al. } \\
\quad[72]\end{array}$ & 2012 & miR-375 & 123 & $\begin{array}{c}\text { Oral Cavity 35\% } \\
\text { Oropharynx 30\% } \\
\text { Larynx 35\% }\end{array}$ & qRT-PCR & US & $\begin{array}{c}\text { Male } \\
(69.1 \%)\end{array}$ & $\begin{array}{l}\mathrm{T} 1+\mathrm{T} 2 \\
(19.5 \%) \\
\mathrm{T} 3+\mathrm{T} 4 \\
(80.5 \%)\end{array}$ & NA & $\begin{array}{c}\text { Smoking } \\
(60.9 \%) \\
\text { Alcohol } \\
(27.6 \%) \\
\text { HPV } \\
(25.2 \%)\end{array}$ & $\begin{array}{c}\leq 58(37 \%) \\
59-66(31 \%) \\
\geq 67(33 \%)\end{array}$ \\
\hline $\begin{array}{c}\text { Huang et al. } \\
\text { [73] }\end{array}$ & 2014 & miR-491-p5 & 33 & Oral Cavity & qRT-PCR, FISH & Taiwan & $\begin{array}{c}\text { Male } \\
(96.9 \%)\end{array}$ & $\begin{array}{c}\text { T1 }(9.1 \%) \\
\text { T2 }(51.5 \%) \\
\text { T3 }(3.0 \%) \\
\text { T4 }(36.4 \%)\end{array}$ & NA & NA & $\begin{array}{l}\leq 60(21 \%) \\
>60(79 \%)\end{array}$ \\
\hline $\begin{array}{c}\text { Shiiba et al. } \\
\text { [74] }\end{array}$ & 2013 & $\operatorname{miR}-125 b$ & 50 & Oral Cavity & qRT-PCR & Japan & NA & $\begin{array}{l}\text { T1 }(10 \%) \\
\text { T2 }(12 \%) \\
\text { T3 }(14 \%) \\
\text { T4 }(64 \%)\end{array}$ & NA & NA & NA \\
\hline
\end{tabular}


Table 1. Cont.

\begin{tabular}{|c|c|c|c|c|c|c|c|c|c|c|c|}
\hline Article & Year & $\operatorname{miR}$ & $\begin{array}{l}\text { Sample } \\
\text { Size }\end{array}$ & Anatomic Location & Assay Method & $\begin{array}{c}\text { Study } \\
\text { Population }\end{array}$ & Gender & Stage & Metastasis & $\begin{array}{c}\text { Risk } \\
\text { Factors }\end{array}$ & Age \\
\hline $\begin{array}{c}\text { Zeng et al. } \\
\text { [75] }\end{array}$ & 2012 & miR-20a & 160 & Nasopharyngeal & qRT-PCR & China & $\begin{array}{l}\text { Male } \\
(61.25 \%)\end{array}$ & $\begin{array}{c}\text { T1 }(1,25 \%) \\
\text { T2 }(15.63 \%) \\
\text { T3 }(34.38 \%) \\
\text { T4 }(40 \%)\end{array}$ & NA & NA & $46.41 \pm 10.74$ \\
\hline Liu et al. [76] & 2013 & $\operatorname{miR}-451$ & 280 & Nasopharyngeal & qRT-PCR & Taiwan & $\begin{array}{l}\text { Male } \\
(73.57 \%)\end{array}$ & $\begin{array}{c}\mathrm{T} 1+\mathrm{T} 2 \\
(50.71 \%) \\
\mathrm{T} 3+\mathrm{T} 4 \\
(49.28 \%)\end{array}$ & NA & NA & $\begin{array}{l}\leq 45(49 \%) \\
>45(51 \%)\end{array}$ \\
\hline $\begin{array}{c}\text { Yang et al. } \\
\text { [77] }\end{array}$ & 2011 & miR-181a & 39 & Oral Cavity & qRT-PCR & Taiwan & $\begin{array}{c}\text { Male } \\
(44.87 \%)\end{array}$ & $\begin{array}{c}\mathrm{T} 1+\mathrm{T} 2+ \\
\mathrm{T} 3(33.33 \%) \\
\mathrm{T} 4(66.66 \%)\end{array}$ & NA & NA & NA \\
\hline Wu et al. [78] & 2014 & miR-19a & 83 & Laryngeal & qRT-PCR & China & $\begin{array}{l}\text { Male } \\
(68.67 \%)\end{array}$ & NA & $\begin{array}{c}\text { Metastases + ve } \\
(34.93 \%)\end{array}$ & NA & $\begin{array}{l}\geq 56(51 \%) \\
<56(49 \%)\end{array}$ \\
\hline $\begin{array}{l}\text { Peng et al. } \\
\text { [79] }\end{array}$ & 2014 & $\begin{array}{c}\text { Let-7g } \\
\text { miR-125b } \\
\text { miR-218 }\end{array}$ & 29 & Oral Cavity & qRT-PCR & Taiwan & NA & NA & NA & NA & NA \\
\hline $\begin{array}{l}\text { Arriagada } \\
\text { et al. [80] }\end{array}$ & 2018 & miR-215b & 32 & Head and Neck & qRT-PCR & Chile & $\begin{array}{l}\text { Male } \\
(55.9 \%)\end{array}$ & $\begin{array}{l}\mathrm{T} 1+\mathrm{T} 2 \\
(75.2 \%) \\
\mathrm{T} 3+\mathrm{T} 4 \\
(47.7 \%)\end{array}$ & NA & $\begin{array}{c}\text { Smoking } \\
(62.5 \%) \\
\text { Drinking } \\
(50.5 \%)\end{array}$ & $\begin{array}{c}<64(86 \%) \\
\geq 64 \text { years } \\
\quad(44 \%)\end{array}$ \\
\hline $\begin{array}{l}\text { Baroudi et al. } \\
\text { [81] }\end{array}$ & 2017 & $\operatorname{miR}-377-3 p$ & 199 & $\begin{array}{c}\text { Larynx } 31 \% \\
\text { Oral cavity } 64 \% \\
\text { Oropharynx } 5 \%\end{array}$ & GSEA & NA & Male $(28 \%)$ & $\begin{array}{c}\text { T1 }(9 \%) \\
\text { T2 }(18 \%) \\
\text { T3 }(27 \%) \\
\text { T4 }(53 \%)\end{array}$ & NA & $\begin{array}{c}\text { Smoking } \\
(52 \%) \\
\text { Alcohol } \\
(66 \%)\end{array}$ & $\begin{array}{c}\leq 70 \text { years } \\
(80 \%) \\
>70 \text { years } \\
(20 \%)\end{array}$ \\
\hline $\begin{array}{l}\text { Berania et al. } \\
\text { [82] }\end{array}$ & 2017 & $\begin{array}{l}\text { miR-18a } \\
\text { miR-548b }\end{array}$ & 58 & $\begin{array}{l}\text { Oral tongue squamous } \\
\text { cell carcinoma }\end{array}$ & qRT-PCR & Canada & Male $(71 \%)$ & NA & NA & $\begin{array}{c}\text { Smoking } \\
\text { (72\%) } \\
\text { Drinking } \\
(41 \%) \mathrm{HPV} \\
(22 \%)\end{array}$ & $\begin{array}{l}\leq 50(28 \%) \\
>50(72 \%)\end{array}$ \\
\hline He et al. [83] & 2017 & miR-300 & 133 & $\begin{array}{l}\text { Laryngeal squamous } \\
\text { cell carcinoma }\end{array}$ & qRT-PCR & China & Male (65\%) & $\begin{array}{c}\mathrm{T} 1+\mathrm{T} 2 \\
(50 \%) \\
\mathrm{T} 3+\mathrm{T} 4 \\
(50 \%)\end{array}$ & $\begin{array}{c}\text { Metastasis + ve } \\
(55 \%)\end{array}$ & NA & $\begin{array}{l}<50(35 \%) \\
\geq 50(65 \%)\end{array}$ \\
\hline
\end{tabular}


Table 1. Cont.

\begin{tabular}{|c|c|c|c|c|c|c|c|c|c|c|c|}
\hline Article & Year & $\operatorname{miR}$ & $\begin{array}{c}\text { Sample } \\
\text { Size }\end{array}$ & Anatomic Location & Assay Method & $\begin{array}{c}\text { Study } \\
\text { Population }\end{array}$ & Gender & Stage & Metastasis & $\begin{array}{c}\text { Risk } \\
\text { Factors }\end{array}$ & Age \\
\hline $\begin{array}{c}\text { Hess et al. } \\
\text { [84] }\end{array}$ & 2017 & $\begin{array}{l}\text { miR-200b } \\
\text { miR-155 } \\
\text { miR-146a }\end{array}$ & 149 & $\begin{array}{l}\text { Oropharynx } 52 \% \\
\text { Hypopharynx } 48 \%\end{array}$ & qRT-PCR & Germany & NA & NA & NA & NA & NA \\
\hline $\begin{array}{c}\text { Jiang et al. } \\
\text { [85] }\end{array}$ & 2017 & $\operatorname{miR}-212$ & 73 & Nasopharyngeal & qRT-PCR & China & Male $(59 \%)$ & $\begin{array}{c}\mathrm{T} 1+\mathrm{T} 2 \\
(34 \%) \\
\mathrm{T} 3+\mathrm{T} 4 \\
(66 \%) \\
\end{array}$ & $\begin{array}{c}\text { Metastasis + ve } \\
(56 \%)\end{array}$ & NA & $\begin{array}{l}\leq 45(48 \%) \\
>45(52 \%)\end{array}$ \\
\hline Liu et al. [86] & 2017 & let-7a & 131 & Thyroid & qRT-PCR & China & Male (33\%) & $\begin{array}{c}\mathrm{T} 1+\mathrm{T} 2 \\
(39 \%) \\
\mathrm{T} 3+\mathrm{T} 4 \\
(61 \%)\end{array}$ & $\begin{array}{c}\text { Metastasis + ve } \\
(53 \%)\end{array}$ & NA & $\begin{array}{l}<45(44 \%) \\
\geq 45(56 \%)\end{array}$ \\
\hline Re et al. [87] & 2017 & $\operatorname{miR}-34 c-5 p$ & 43 & $\begin{array}{c}\text { Supraglottic }(18.60 \%) \\
\text { Transglottic }(76.74 \%) \\
\text { Subglottic }(4.65 \%)\end{array}$ & qRT-PCR & Italy & $\begin{array}{l}\text { Male } \\
(97.67 \%)\end{array}$ & $\begin{array}{l}\text { T3 }(72 \%) \\
\text { T4 }(28 \%)\end{array}$ & $\begin{array}{c}\text { Metastasis + ve } \\
(0 \%)\end{array}$ & NA & $66.51 \pm 8.02$ \\
\hline $\begin{array}{l}\text { Romeo et al. } \\
{[88]}\end{array}$ & 2018 & miR-375 & 36 & Medullary thyroid & qRT-PCR & Italy & $\begin{array}{l}\text { Male } \\
(58.3 \%)\end{array}$ & $\begin{array}{c}\mathrm{T} 1+\mathrm{T} 2 \\
(25 \%) \\
\mathrm{T} 3+\mathrm{T} 4 \\
(63.8 \%)\end{array}$ & $\begin{array}{l}\text { Metastasis + ve } \\
(72.2 \%)\end{array}$ & NA & Mean 55.5 \\
\hline $\begin{array}{l}\text { Wilkins et al. } \\
\text { [89] }\end{array}$ & 2018 & $\begin{array}{c}\text { miR-100 } \\
\text { miR-125b } \\
\text { Let-7a }\end{array}$ & 2083 & $\begin{array}{c}\text { Oral cavity }(31.7 \%) \\
\text { Pharynx }(52.7 \%) \\
\text { Larynx }(15.6 \%)\end{array}$ & $\begin{array}{l}\text { Axiom miRNA Target } \\
\text { Site Genotyping Array }\end{array}$ & USA & $\begin{array}{l}\text { Male } \\
(24.5 \%)\end{array}$ & $\begin{array}{l}\mathrm{T} 1+\mathrm{T} 2 \\
(25.9 \%) \\
\mathrm{T} 3+\mathrm{T} 4 \\
(74.1 \%)\end{array}$ & NA & $\begin{array}{c}\text { Smoking } \\
\text { [current] } \\
(25.9 \%) \\
\text { Smoking } \\
\text { [former] } \\
(42.9 \%)\end{array}$ & $\begin{array}{c}\leq 50(24.8 \%) \\
>50 \text { to } \leq 60 \\
(36.2 \%) \\
>60 \text { to } \leq 70 \\
(25.9 \%) \\
>70(13.1 \%)\end{array}$ \\
\hline Yu et al. [90] & 2017 & $\mathrm{miR}-21$ & 100 & $\begin{array}{c}\text { Buccal mucosa }(37 \%) \\
\text { Tongue }(35 \%) \\
\text { Mouth floor }(12 \%) \\
\text { Others }(16 \%)\end{array}$ & Immunohistochemistry & China & Male $(92 \%)$ & $\begin{array}{c}\mathrm{T} 1+\mathrm{T} 2 \\
(23 \%) \\
\mathrm{T} 3+\mathrm{T} 4 \\
(77 \%)\end{array}$ & $\begin{array}{c}\text { Metastasis + ve } \\
(28 \%)\end{array}$ & NA & $\begin{array}{l}\leq 55(56 \%) \\
>55(44 \%)\end{array}$ \\
\hline
\end{tabular}


Meta-Analysis of upregulated miRNAs Expression for Overall Survival in HNC

\begin{tabular}{|c|c|c|c|c|c|}
\hline \multirow[t]{2}{*}{ Study name } & \multirow[b]{2}{*}{$\begin{array}{l}\text { Hazard } \\
\text { ratio }\end{array}$} & \multicolumn{3}{|c|}{ Statistics for each study } & \multirow[b]{2}{*}{$\mathrm{p}$-Value } \\
\hline & & $\begin{array}{c}\text { Lower } \\
\text { limit }\end{array}$ & $\begin{array}{l}\text { Upper } \\
\text { limit }\end{array}$ & Z-Value & \\
\hline Arantes et. al. (2017) [21] & 2.050 & 1.048 & 4.011 & 2.097 & 0.036 \\
\hline Arrigagada et. al. (2018) [125b] & ]] 6.370 & 1.781 & 22.781 & 2.848 & 0.004 \\
\hline Avissar et. al. (2009) [21] & 1.680 & 1.029 & 2.742 & 2.075 & 0.038 \\
\hline Baroudi et. al. (2017) [377-3p] & 1.190 & 0.542 & 2.612 & 0.434 & 0.665 \\
\hline Berania et al. (2017) [18a] & 10.170 & 2.060 & 50.210 & 2.847 & 0.004 \\
\hline Childs et. al. (2009) [21] & 0.670 & 0.338 & 1.327 & -1.148 & 0.251 \\
\hline Gee et. al. (2010) [21] & 1.230 & 0.681 & 2.221 & 0.687 & 0.492 \\
\hline Hudcova et. al. (2016) [375] & 1.320 & 0.762 & 2.287 & 0.990 & 0.322 \\
\hline Jung et. al. (2012) [21] & 3.340 & 1.101 & 10.132 & 2.130 & 0.033 \\
\hline Ko et. al. (2014) [21] & 2.970 & 1.339 & 6.589 & 2.678 & 0.007 \\
\hline Li et. al. (2009) [21] & 1.540 & 1.082 & 2.192 & 2.397 & 0.017 \\
\hline Li et. al. (2015) [93] & 0.515 & 0.265 & 1.001 & -1.957 & 0.050 \\
\hline Liao et. al. (2015) [1246] & 2.820 & 1.070 & 7.431 & 2.097 & 0.036 \\
\hline Lin et. al. (2014) [206] & 6.245 & 1.746 & 22.334 & 2.817 & 0.005 \\
\hline Liu et al. (2017) [let-7a] & 1.700 & 1.322 & 2.187 & 4.132 & 0.000 \\
\hline Luo et. al. (2013) [18a] & 2.411 & 1.284 & 4.529 & 2.736 & 0.006 \\
\hline Romeo et al. (2018) [375] & 7.030 & 2.787 & 17.732 & 4.131 & 0.000 \\
\hline Shi et. al. (2014) [155] & 1.748 & 0.508 & 6.015 & 0.886 & 0.376 \\
\hline Wilkins et al. (2018) [100] & 1.250 & 1.054 & 1.482 & 2.567 & 0.010 \\
\hline Wilkins et. al. (2018) [125b] & 1.040 & 0.823 & 1.315 & 0.328 & 0.743 \\
\hline Wilkins et. al. (2018) [Let-7a] & 0.920 & 0.741 & 1.142 & -0.756 & 0.450 \\
\hline Wu et. al. (2014) [19a] & 2.260 & 1.352 & 3.778 & 3.110 & 0.002 \\
\hline Wu et. al. (2014) [9] & 3.180 & 1.024 & 9.873 & 2.001 & 0.045 \\
\hline Xu et. al. (2015) [483-5p] & 2.320 & 1.249 & 4.310 & 2.663 & 0.008 \\
\hline Zeng et. al. (2012) & 682 & 1.992 & 16.206 & 3.249 & 0.001 \\
\hline & 1.7 & .43 & 2.168 & 5.352 & 0.000 \\
\hline
\end{tabular}

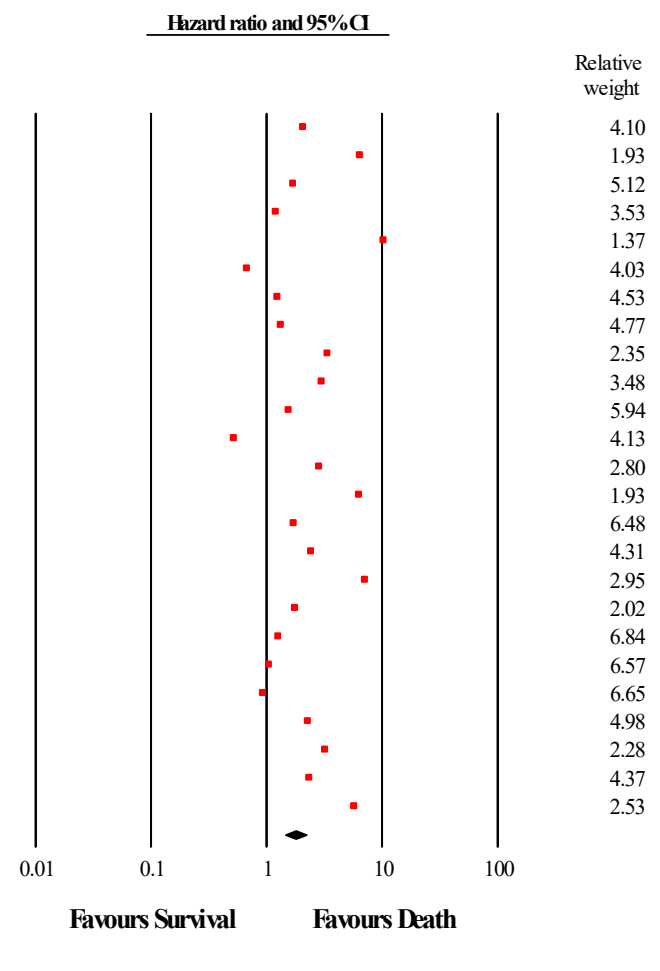

(A)

Meta-Analysis of Downregulated miRNAs Expression for Overall Survival in HNC

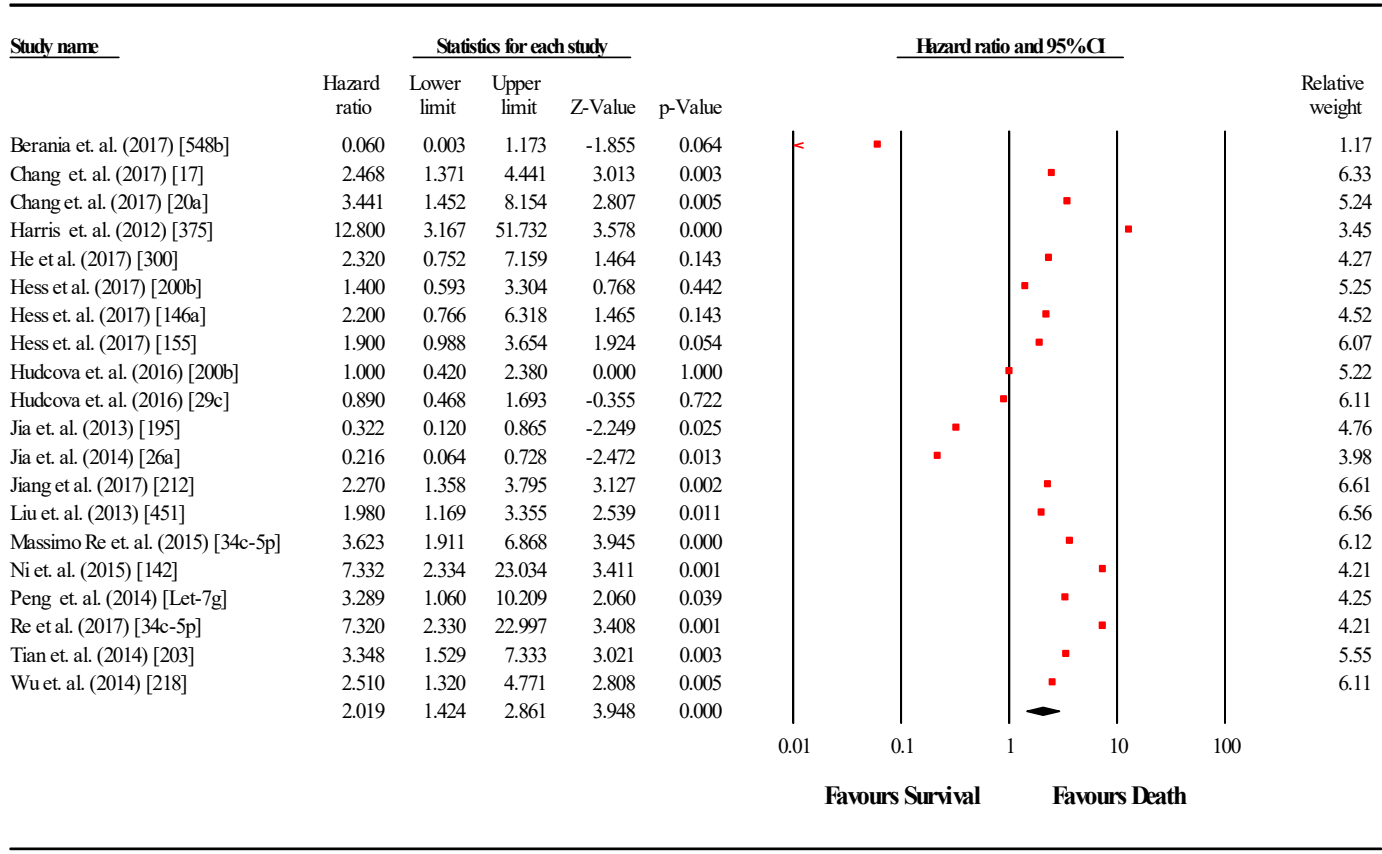

(B)

Figure 2. Forest plots for the miRNAs associated with OS. (A) Upregulated miRNA; (B) Downregulated miRNA. 
Meta-Analysis of Upregulated and Downregulated miRNAs Expression for Disease Free Survival in HNC

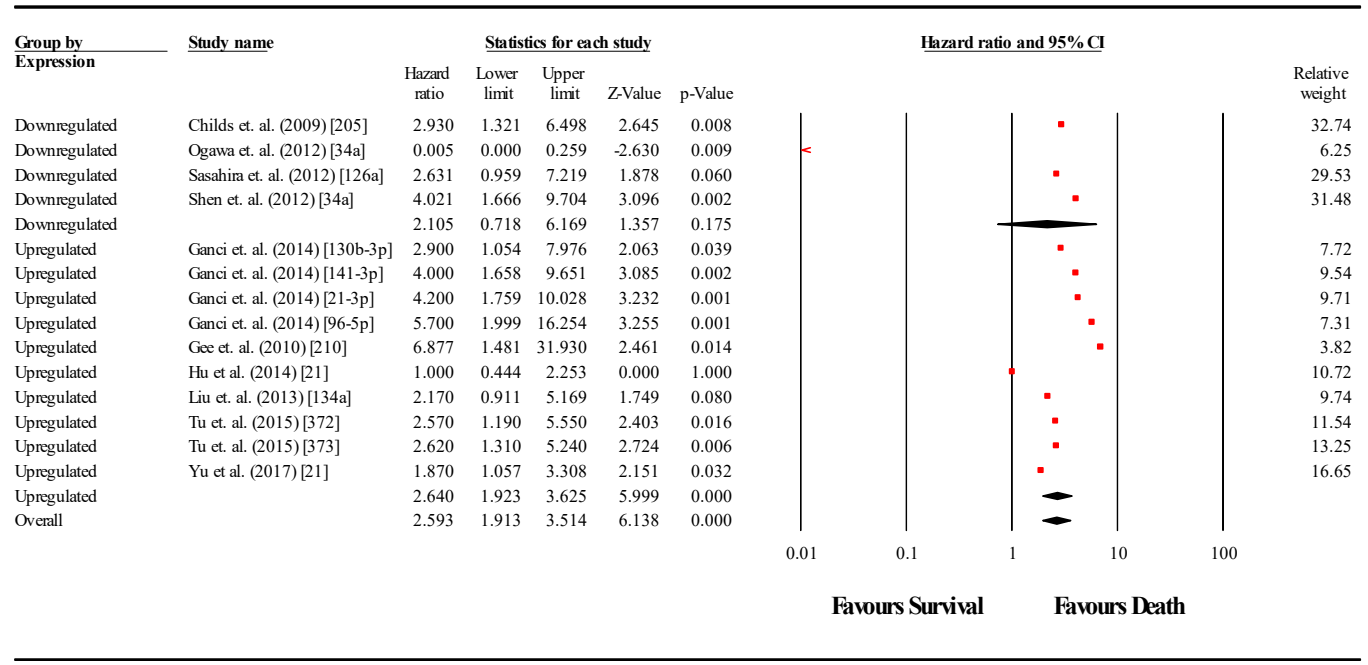

Figure 3. Forest plot for the miRNAs associated with DFS.

For DFS, the upregulated miRNA cohort $(n=10)$ showed a pooled effect estimate (HR) of 2.641 (95\% CI 1.925-3.623; $p<0.05)$, while the downregulated miRNA cohorts $(n=4)$ showed a pooled effect estimate (HR) of $2.135(0.730-6.179 ; p>0.05)$. Although the pooled effect estimate of studies assessing upregulated miRNA was statistically significant, the same was not observed in the downregulated miRNA studies. For the meta-analysis analysing the effect of downregulated miRNA on DFS, three out of the four cohorts indicated a lower probability of survival and were consistent, while a single study by Ogawa et al [57] was observed to be contradictory to the three studies above, and served to severely skew the overall pooled results. As three of the four studies were consistent with a reduced probability of survival, it is likely that the single study is the outlier, disregarding which, the pooled effect estimate of the three cohorts alone was found to be statistically significant $(p<0.05)$.

\subsection{2. miRNA Subgroups}

miRNA subgroups were selected based on the miRNA that was frequently represented in multiple cohorts across all studies included in the meta-analysis. miRNA subgroups were also assessed separately based on the survival endpoints (OS and DFS). The miRNA subgroups assessed are miR-21, 155, 200b, 18a, 34c-5p, 125b, 20a, and 375 for the OS group (Supplementary Figure S1A-H) and miR-21, and 34a for the DFS group (Supplementary Figure S2A,B).

\subsection{Overall Survival Group}

\subsection{1. $\mathrm{miR}-21$}

A total of 7 studies assessed miR-21 expression in HNC patients in this group (Figure 4). All seven studies showed that miR-21 is upregulated in HNC patients. The pooled effect size estimate (HR) was found to be $1.591(1.154-2.194 ; p<0.05)$. The pooled effect estimate was statistically significant. Of the seven studies, six showed that upregulated miR-21 expression leads to a lower probability of survival, while a single study presented an outlier result, indicating the opposite. $\left(\mathrm{I}^{2}=48.122\right.$; $\mathrm{Tau}^{2}=0.085$; Cochran's $Q=11.566)$. 


\section{Subgroup Analysis of Upregulated miRNA-21 Expression for Overall Survival in HNC}

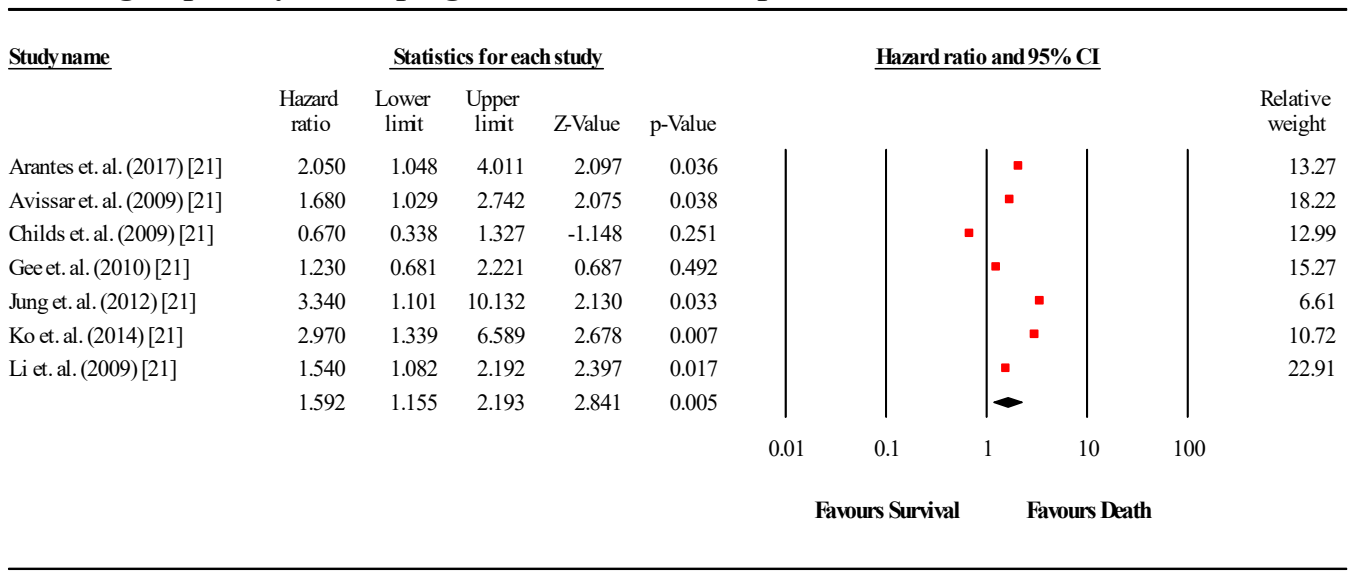

Figure 4. Forest plot for miR-21 association with OS.

\subsection{2. $\mathrm{miR}-200 \mathrm{~b}$}

A total of 2 studies assessed miR-200b expression in HNC patients in this group (Figure 5). Both studies showed that miRNA-200b is downregulated in HNC patients. The pooled effect size estimate (HR) was found to be 1.185 (95\% CI 0.644-2.182). Both studies individually did not present statistically significant results, and the pooled effect size estimate (HR) was similarly found to be non-significant. $\left(\mathrm{I}^{2}=0.00 ; \mathrm{Tau}^{2}=0.00\right.$; Cochran's $\left.Q=0.292\right)$.

Subgroup Analysis of Downregulated miRNA-200b Expression for Overall Survival in HNC

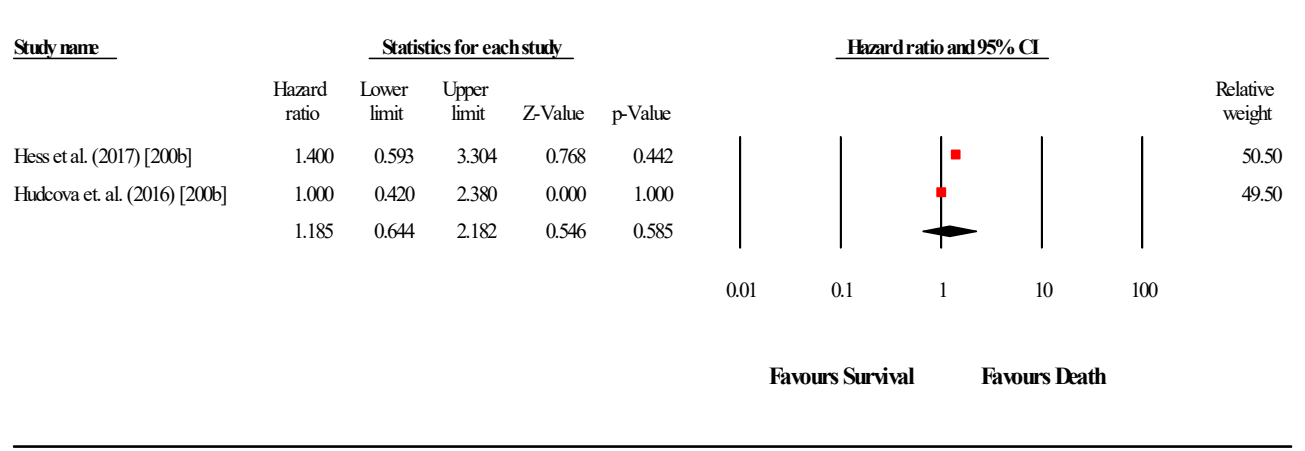

Figure 5. Forest plot for miR-200b association with OS.

\subsection{3. $\mathrm{miR}-155$}

A total of two studies assessed miR-155 expression in HNC patients (Figure 6). The two studies showed contradicting results regarding miR-155 expression in HNC, with the Hess et al. (2017) study indicating that miR-155 is downregulated in HNC, while the Shi et al. (2015) study claimed that miR-155 is upregulated in HNC. The pooled effect estimate (HR) was found to be statistically significant, with a value of 1.866 (95\% CI 1.047-3.326; $p<0.05)$. However, contradicting results of the individual studies limits the applicability of these results to all HNC cases $\left(\mathrm{I}^{2}=0.00\right.$; $\mathrm{Tau}^{2}=0.00$; Cochran's $Q=0.014)$. 


\section{Subgroup Analysis of miRNA-155 Expression for Overall Survival in HNC}

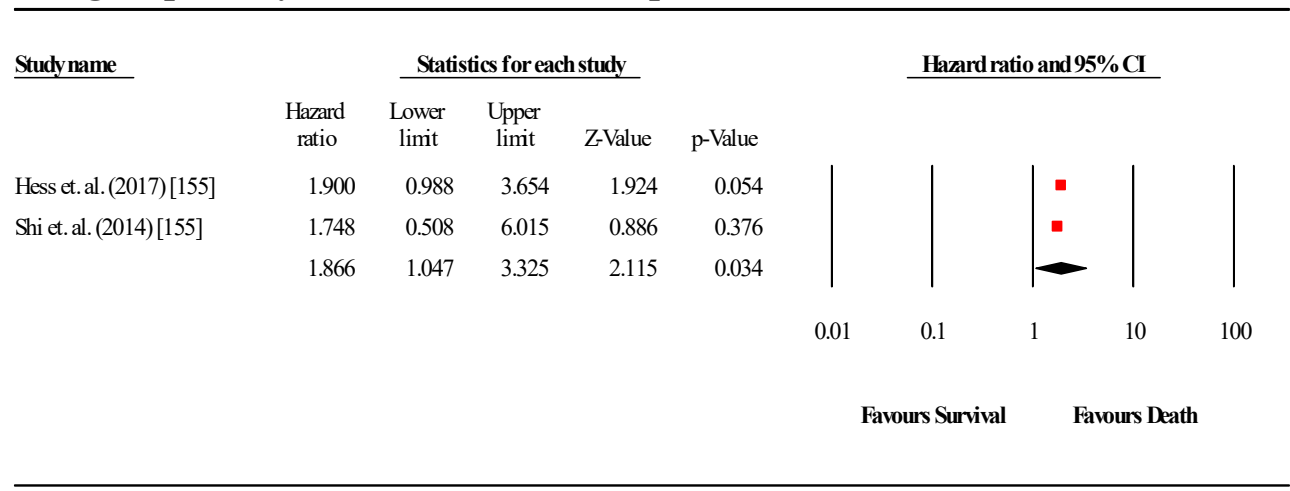

Figure 6. Forest plot for miR-155 association with OS.

\subsection{4. $\mathrm{miR}-18 \mathrm{a}$}

A total of 2 studies assessed miR-18a expression in HNC patients (Figure 7). Both studies indicated that miR-18a is upregulated in HNC. The pooled effect estimate (HR) was found to be statistically significant, with a value of 1.866 (95\% CI 1.047-3.326; $p<0.05)$. $\left(\mathrm{I}^{2}=62.964 ; \mathrm{Tau}^{2}=0.652\right.$; Cochran's $Q=2.7)$.

\section{Subgroup Analysis of miRNA-18a Expression for Overall Survival in HNC}

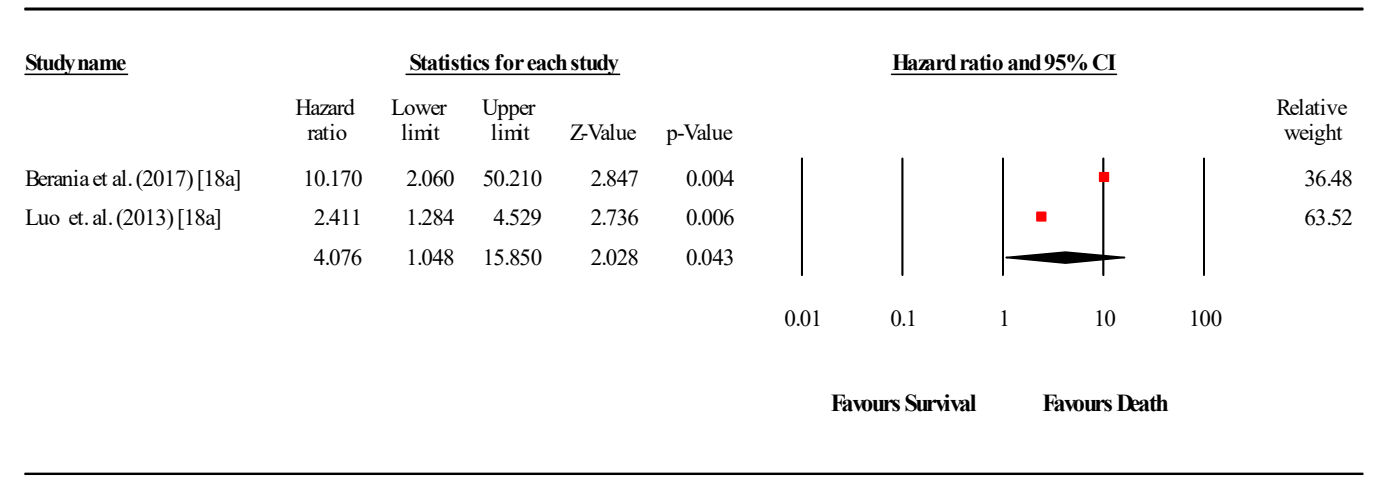

Figure 7. Forest plot for miR-18a association with OS.

\subsection{5. $\mathrm{miR}-34 \mathrm{c}-5 \mathrm{p}$}

A total of 2 studies assessed miR-34c-5p expression in HNC patients (Figure 8). Both studies indicated that miR-34c-5p is downregulated in HNC patients. The pooled effect estimate (HR) was found to be statistically significant, with a value of 4.358 (95\% CI 2.376-7.995; $p<0.05)$. ( $\mathrm{I}^{2}=9.506$; $\mathrm{Tau}^{2}=0.024$; Cochran's $Q=1.105$ ).

\subsection{6. $\mathrm{miR}-125 \mathrm{~b}$}

A total of 2 studies assessed miR-125b expression in HNC patients (Figure 9). Both studies indicated that miR-125b is upregulated in HNC patients. The pooled effect estimate (HR) was found to be 2.3 (95\% CI 0.395-13.397; $p>0.05$ ). The results were not statistically significant, although, of the two studies, the Arrigagada et al. (2018) study was found to be statistically significant, indicating miR-125b upregulation leads to a lower probability of patient survival, while the Wilkins et al. (2018) study did not reject the null hypothesis. $\left(\mathrm{I}^{2}=86.696\right.$; $\mathrm{Tau}^{2}=1.424$; Cochran's $\left.Q=7.516\right)$. 
Subgroup Analysis of miRNA-34c-5p Expression for Overall Survival in HNC

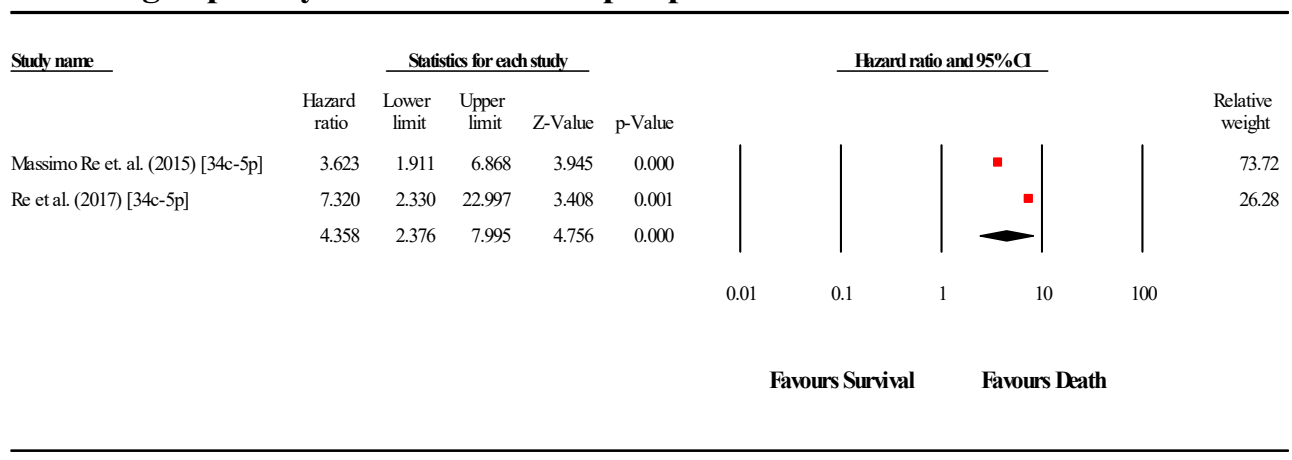

Figure 8. Forest plot for miR-34c-5p association with OS.

Subgroup Analysis of miRNA-125b Expression for Overall Survival in HNC

\begin{tabular}{lcccrrr} 
Study name & \multicolumn{5}{c}{ Statistics for eachstudy } & \\
\cline { 3 - 6 } & $\begin{array}{c}\text { Hazard } \\
\text { ratio }\end{array}$ & $\begin{array}{c}\text { Lower } \\
\text { limit }\end{array}$ & $\begin{array}{c}\text { Upper } \\
\text { limit }\end{array}$ & Z-Value & p-Value \\
Arrigagada et. al. (2018) [125b] & 6.370 & 1.781 & 22.781 & 2.848 & 0.004 \\
Willkns et. al. (2018) [125b] & 1.040 & 0.823 & 1.315 & 0.328 & 0.743 \\
& 2.300 & 0.395 & 13.397 & 0.926 & 0.354
\end{tabular}

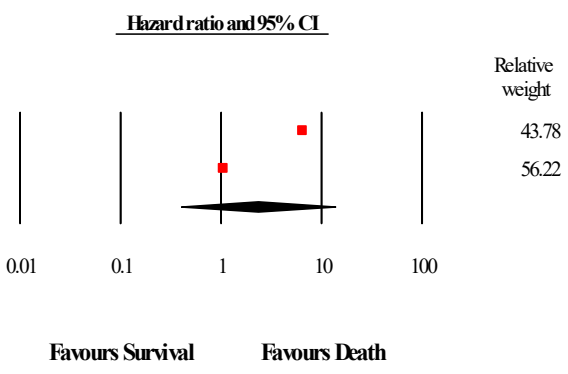

Figure 9. Forest plot for miR-125b for association with OS.

\subsection{7. $\mathrm{miR}-20 \mathrm{a}$}

A total of two studies assessed miR-20a expression in HNC patients (Figure 10). The two studies showed contradicting results regarding miR-20a expression in $\mathrm{HNC}$, with the Chang et al. (2017) study indicating that miR-20a is downregulated in HNC, while the Zeng et al. (2012) study claimed that miR-20a is upregulated in HNC. The pooled effect estimate (HR) was found to be statistically significant, with a value of 4.214 (95\% CI 2.165-8.203; $p<0.05)$. However, contradicting results of the individual studies limits the applicability of these results to all $\mathrm{HNC}$ cases. $\left(\mathrm{I}^{2}=0.00\right.$; $\mathrm{Tau}^{2}=0.00$; Cochran's $Q=0.524)$.

\section{Subgroup Analysis of miRNA-20a Expression for Overall Survival in HNC}

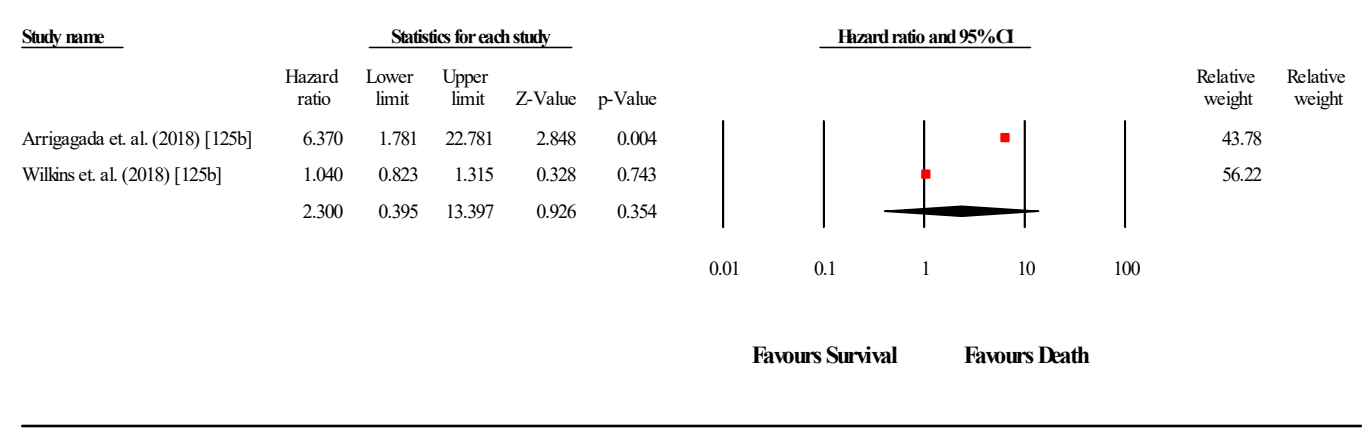

Figure 10. Forest plot for miR-20a association with OS.

\subsection{8. $\mathrm{miR}-375$}

A total of 3 studies assessed miR-375 expression in HNC patients (Figure 11). Of the three studies, two indicated that miR-375 is upregulated in HNC, while 1 study by Harris et al. (2012) claimed that 
miR-375 is downregulated in HNC patients. The overall pooled effect estimate (HR) was statistically significant, with a value of 4.482 (95\% CI 1.049-19.145). Individually, only the Harris et al. (2012) study results did not reject the null hypothesis, while the remaining two studies individually showed a high degree of statistical significance. Therefore, we may consider the Harris et al. (2012) study as the outlier in this group of studies. $\left(\mathrm{I}^{2}=86.872\right.$; Tau $^{2}=1.395$; Cochran's $\left.Q=15.235\right)$.

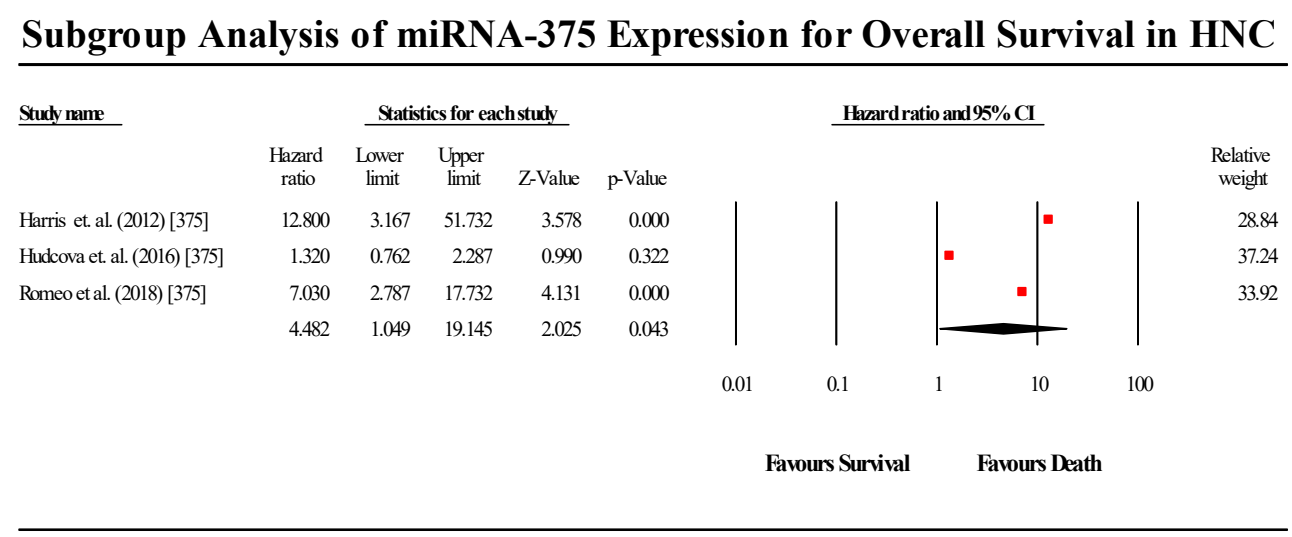

Figure 11. Forest plot for miR-375 association with OS.

\subsection{Disease-Free Survival Group}

\subsection{1. $\mathrm{miR}-21$}

A total of two studies assessed miR-21 expression in HNC patients in this group (Figure 12). Both studies indicated that miR-21 is upregulated in HNC. The pooled effect size estimate (HR) was found to be 1.466 (95\% CI 0.806-2.666; $p>0.05)$. The pooled results were not statistically significant. $\left(\mathrm{I}^{2}=\right.$ 34.5; $\mathrm{Tau}^{2}=0.068$; Cochran's $\left.Q=1.527\right)$.

\section{Subgroup-analysis of Upregulated miRNA-21 expression in HNC (DFS)}

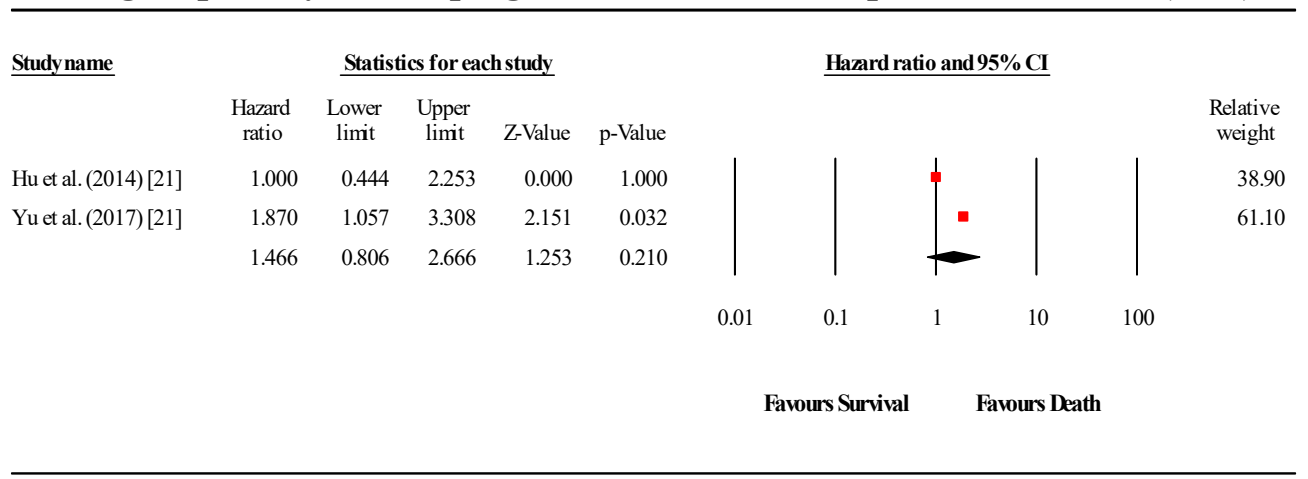

Figure 12. Forest plot for miR-21 association with DFS.

\subsection{2. $\mathrm{miR}-34 \mathrm{a}$}

A total of two studies assessed miR-34a expression in HNC patients in this group (Figure 13). Both studies indicated that miR-34a is downregulated in HNC. The pooled effect size estimate (HR) was found to be 0.190 (95\% CI 0.001-130.514; $p>0.05)$. The results were not found to be statistically significant. ( $\mathrm{I}^{2}=90.317$; $\mathrm{Tau}^{2}=20.210$; Cochran's $\left.Q=10.327\right)$. 


\section{Subgroup-analysis of Downregulated miRNA-34a expression in HNC (DFS)}

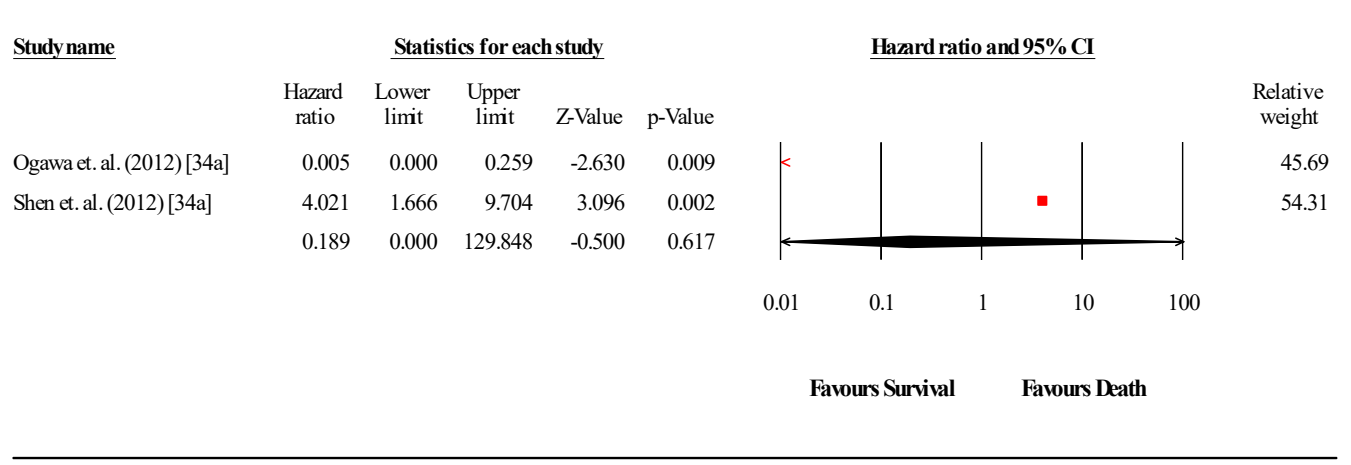

Figure 13. Forest plot for miR-34a association with DFS.

\subsection{Publication Bias}

The Egger's graphical test was used to assess for publication bias. The funnel plot was constructed alongside the meta-analysis using the CMA software (Ver 3.3.070, USA). The funnel plots provided in Figures 14 and 15 visually represent the likelihood of publication bias in the OS and DFS groups, respectively, of this systematic review and meta-analysis study. The funnel plot for OS was observed to be slightly asymmetric with a more significant number of studies falling on the right of the line of mean effect. Trim and fill was used to impute for possible missing studies, which led to the imputation of 12 missing studies, adjusting the point estimate and its 95\% CI from 1.90043 (1.58306-2.28143) to 1.21935 (1.17451-1.71522), after imputation. Orwin's Fail-safe $\mathrm{N}$ test did not apply to this assessment of publication bias, since the HR of observed studies did not fall between the HRs of the missing studies. Begg and Mazumdar's rank correlation test presented a Kendall's Tau value of 0.21919, with continuity correction. For the DFS group, the funnel plot was relatively symmetrical, with the trim and fill required to adjust for two missing studies. Overall, publication bias was not found to have any significant impact on the results of this meta-analysis.

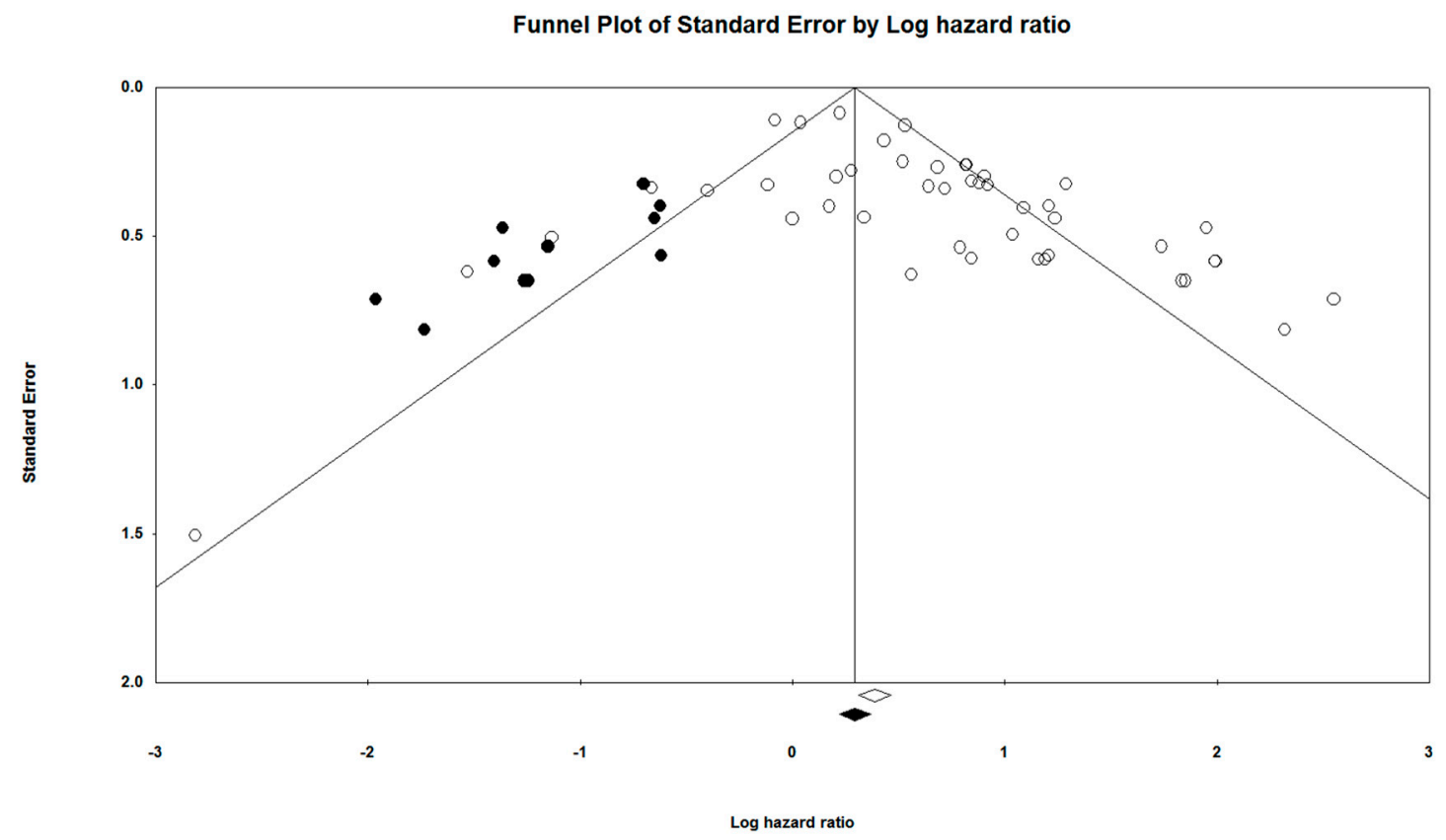

Figure 14. Funnel plot for the studies prognostic of OS. 
Funnel Plot of Standard Error by Log hazard ratio

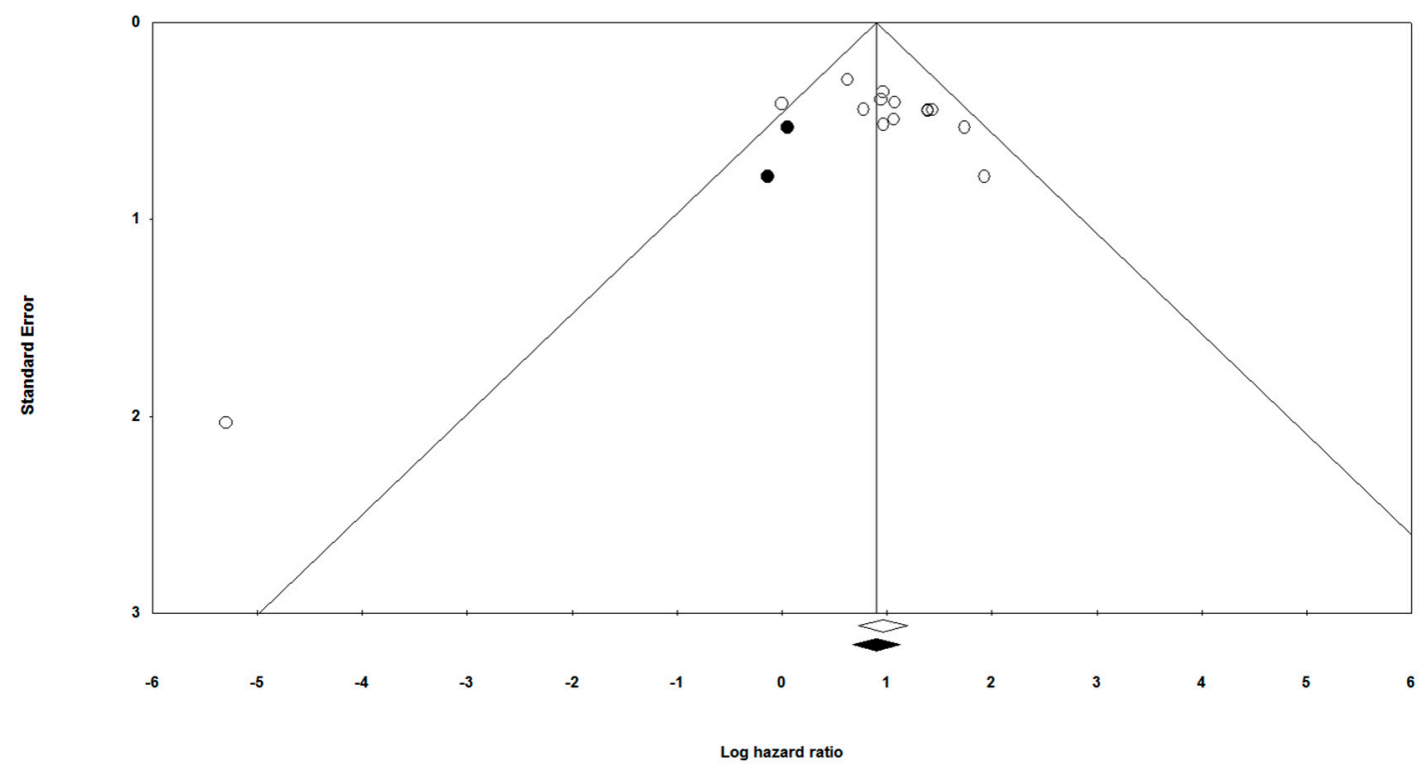

Figure 15. Funnel plot for the studies prognostic of DFS.

\subsection{Quality Assessment}

The NHLBI Quality Assessment Tool for Observational Cohort and Cross-Sectional Studies was used to assess the quality of included studies. A majority of the studies had good quality scores (38/50), with all the rest having satisfactory scores. However, the core requirement for inclusion into the meta-analysis was based on the availability of good quality statistical data (HR and 95\% CI).

\section{Discussion}

This systematic review and meta-analysis were conducted to investigate the prognostic potential of miRNA as biomarkers in HNC, via exploring the association between miRNA expression and survival in HNC patients. The use of miRNAs as prognostic markers in HNC has been the subject of much research, with previous studies reporting that miRNAs have both tumour-suppressing and oncogenic roles and may be either upregulated or downregulated in HNC patients. Therefore, in lieu of miRNAs impact upon cancer progression, they have also been proposed as potential biomarkers predicting patient prognosis. Previous studies have pursued this thread of logic, and have attempted to identify miRNAs that may have the capacity of being utilised as prognostic markers. However, despite this, no new miRNAs have been proposed as prognostic markers in HNC. Furthermore, no previous study has attempted to explore the prognostic potential of multiple miRNAs, as well as explore the impact on HNC based on the magnitude and direction of the deregulation of miRNA expression. This study is the first systematic review and meta-analysis on this topic to have assessed such a wide variety of miRNA and assessed their capacity to act as prognostic markers.

A previous study has also conducted a similar systematic review and meta-analysis [6]. However, the study only focused on miR-21 as a potential prognostic marker in HNC and did not explore the impact or differences of upregulation or downregulation of miRNA on the prognosis of HNC patients. Another previous meta-analysis study was conducted, regarding HNC and miRNA, but focused on the molecular network aspects of miRNA and cancer rather than the clinical utility of miRNA.

This systematic review and meta-analysis of 50 studies involving 6843 patients, investigating the prognostic value of 43 different miRNA summarises the results via pooled HR values as the effect size estimate of the study. While all miRNA were assessed in a combined meta-analysis to observe their prognostic potential of miRNA as a whole, a few select miRNAs were individually assessed to 
identify and highlight the specific miRNA which may have potential clinical utility. These miRNA were miR-21, 200b, 155, 18a, 34c-5p, 125b, 20a, 375 and 34a.

While multiple studies were pooled for miR-21 and miR-375, only two cohorts each were pooled for the rest of the miRNAs. miR-21 has been reported as an oncogenic factor and a potential prognostic marker indicating a poor prognosis in multiple types of cancers. Therefore, even though miR-21 is well known for its prognostic potential in cancers, it is not specific to detecting HNC, and is therefore not an ideal miRNA for HNC prognosis in particular. miR-375 is similarly found to be expressed in several cancer types, thereby indicating its lack of specificity. Nevertheless, miR-21 and 375 are dominant miRNA markers for cancer in general and could be considered as prognostic markers for HNC in conjunction with other cancers.

miR-155 and 20a have significant HR values; however, the conflicting reports of the individual studies regarding whether they are upregulated or downregulated hampers their potential for use in the clinical scenario. This uncertainty requires further investigation in longitudinal cohort studies, where the effect of miR-155 and 20a in HNC is further verified, and consistent results are observed.

miR-200b and $125 \mathrm{~b}$ have effect sizes that are non-significant and do not reject the null hypothesis. This implies that both these miRNAs have a low power of detection, and may not be suitable for use as prognostic markers. However, future studies with larger patient cohorts presenting significant results concerning miR-200b and 125b may serve to highlight the prognostic potential of these miRNA.

miR-18a and 34c-5p are miRNAs offer great potential for prognostic markers in HNC. The effect size values of the pooled results for both miRNAs are significant, as well as high in magnitude, indicating a high power of prognosis. However, as the meta-analysis for these two miRNA was conducted based on the pooling of only two studies each, further verification in future studies is necessary.

This study does have a few limitations [34,91-93]. Ideally, meta-analysis should be conducted on all miRNA included in the study. However, this is limited by the quantity of high-quality literature and data that is published in this field. Additionally, this same limitation also makes accounting for other subgroups such as ethnicity, gender and age impossible, as forming these subgroups would fragment the data even further, such that no analysis can be conducted. This meta-analysis was also conducted using $\mathrm{HR}$ and $95 \% \mathrm{CI}$ values extracted from KM curves, which requires approximations to be made during the extraction process, thus introducing some degree of error into the study.

Overall, this systematic review and meta-analysis highlight the miRNA that may have the potential for use as prognostic biomarkers in HNC patients. As the pool of available literature regarding this topic continues to expand, recognizing the influence of miRNAs as a whole and select miRNA specifically may facilitate the transfer of the prognostic value of miRNA from the hypothetical to the clinical sphere of HNC treatment and prognosis.

\section{Conclusions}

The study highlights miR-21, 375, 155, 18a, 34c-5p, 125b, 20a and 375 as miRNA markers that may have the potential for clinical use as prognostic markers in HNC. However, further validation is imperative before we can confirm their utility. Although a few of the miRNA have shown significant results concerning impacting patient survival, the small number of studies that have been pooled to generate the results reduces their applicability in the clinical sphere. Therefore, further large scale and longitudinal patient studies focusing on these miRNA are required.

Supplementary Materials: The following are available online at http://www.mdpi.com/2073-4409/8/8/772/s1. Table S1. Prisma checklist, Table S2. Hypothesis testing table for OS (Overall Survival) and DFS (Disease Free Survival), Table S3. Hypothesis testing table for individual miRNA under the endpoints of OS and DFS.

Author Contributions: R.J. and C.K. contributed to the conceptualisation, study design, search strategy, protocol development, and review by revising different versions. R.J., C.K., M.R.M., S.S., S.B., A.G., S.K. and K.M.G. provided input into the study design, supervision, ensured the absence of errors and arbitrated in case of disagreement. C.K., M.R.M., S.S. and R.J. engaged in initial searches to determine the feasibility, data collection, analysis and drafting the manuscript. All authors read and approved the final version of the manuscript.

Funding: This work was not supported by any funding source. 
Acknowledgments: We would like to acknowledge the meta-analysis concepts and applications workshop manual by Michael Borenstein for his guidelines on reporting meta-analysis, subgroup analysis and publication bias, (www.meta-analysis-workshops.com).

Conflicts of Interest: The authors declare no competing interests.

\section{References}

1. Jemal, A.; Bray, F.; Center, M.M.; Ferlay, J.; Ward, E.; Forman, D. Global cancer statistics. Ca A Cancer J. Clin. 2011, 61, 69-90. [CrossRef] [PubMed]

2. Dhull, A.K.; Atri, R.; Dhankhar, R.; Chauhan, A.K.; Kaushal, V. Major Risk Factors in Head and Neck Cancer: A Retrospective Analysis of 12-Year Experiences. World J. Oncol. 2018, 9, 80-84. [CrossRef] [PubMed]

3. Mehanna, H.; West, C.M.L.; Nutting, C.; Paleri, V. Head and neck cancer-Part 2: Treatment and prognostic factors. Bmj 2010, 341, c4690. [CrossRef] [PubMed]

4. Denaro, N.; Merlano, M.C.; Russi, E.G. Follow-up in head and neck cancer: Do more does it mean do better? A systematic review and our proposal based on our experience. Clin. Exp. Otorhinolaryngol. 2016, 9, 287. [CrossRef] [PubMed]

5. Mehanna, H.; Kong, A.; Ahmed, S.K. Recurrent head and neck cancer: United Kingdom National Multidisciplinary Guidelines. J. Laryngol. Otol. 2016, 130, S181-S190. [CrossRef] [PubMed]

6. Jamali, Z.; Asl Aminabadi, N.; Attaran, R.; Pournagiazar, F.; Ghertasi Oskouei, S.; Ahmadpour, F. MicroRNAs as prognostic molecular signatures in human head and neck squamous cell carcinoma: A systematic review and meta-analysis. Oral Oncol. 2015, 51, 321-331. [CrossRef] [PubMed]

7. Macfarlane, L.-A.; Murphy, P.R. MicroRNA: Biogenesis, Function and Role in Cancer. Curr. Genom. 2010, 11, 537-561. [CrossRef] [PubMed]

8. Xie, Y.; Ma, X.; Chen, L.; Li, H.; Gu, L.; Gao, Y.; Zhang, Y.; Li, X.; Fan, Y.; Chen, J. MicroRNAs with prognostic significance in bladder cancer: A systematic review and meta-analysis. Sci. Rep. 2017, 7, 5619. [CrossRef]

9. Gu, W.; Xu, Y.; Xie, X.; Wang, T.; Ko, J.H.; Zhou, T. The role of RNA structure at 5' untranslated region in microRNA-mediated gene regulation. RNA 2014, 20, 1369-1375. [CrossRef]

10. Felekkis, K.; Touvana, E.; Stefanou, C.; Deltas, C. microRNAs: A newly described class of encoded molecules that play a role in health and disease. Hippokratia 2010, 14, 236-240.

11. Wahid, F.; Shehzad, A.; Khan, T.; Kim, Y.Y. MicroRNAs: Synthesis, mechanism, function, and recent clinical trials. Biochim. Biophys. Acta (Bba)-Mol. Cell Res. 2010, 1803, 1231-1243. [CrossRef] [PubMed]

12. Schoof, C.R.G.; Botelho, E.L.d.S.; Izzotti, A.; Vasques, L.D.R. MicroRNAs in cancer treatment and prognosis. Am. J. Cancer Res. 2012, 2, 414-433. [PubMed]

13. Khawar, M.B.; Fatima, N.; Abbasi, M.H.; Mehmood, R.; Suqaina, S.K.; Sheikh, N. Head and neck cancer: Epidemiology and role of microRNAs. In Diagnosis and Management of Head and Neck Cancer; IntechOpen: Rijeka, Croatia, 2017.

14. Moher, D.; Liberati, A.; Tetzlaff, J.; Altman, D.G.; Group, P. Preferred reporting items for systematic reviews and meta-analyses: The PRISMA statement. PLoS Med. 2009, 6, e1000097. [CrossRef] [PubMed]

15. National Heart, L.a.B.I. Quality Assessment Tool for Observational Cohort and Cross-Sectional Studies. Available online: https://www.nhlbi.nih.gov/health-topics/study-quality-assessment-tools (accessed on 12 February 2018).

16. Borenstein, M.; Rothstein, H. Comprehensive Meta-Analysis; Biostat: Englewood, NJ, USA, 1999.

17. Hedges, L.V.; Vevea, J.L. Fixed-and random-effects models in meta-analysis. Psychol. Methods 1998, 3, 486. [CrossRef]

18. Higgins, J.P.T.; Thompson, S.G.; Deeks, J.J.; Altman, D.G. Measuring inconsistency in meta-analyses. BMJ 2003, 327, 557-560. [CrossRef] [PubMed]

19. Cochran, W.G. The comparison of percentages in matched samples. Biometrika 1950, 37, 256-266. [CrossRef] [PubMed]

20. Deeks, J.J.; Higgins, J.P.T.; Altman, D.G. Analysing data and undertaking meta-analyses. In Cochrane Handbook for Systematic Reviews of Interventions; Cochrane Book Series; Cochrane Collaboration: London, UK, 2008; pp. 243-296.

21. Von Hippel, P.T. The heterogeneity statistic I(2) can be biased in small meta-analyses. BMC Med. Res. Methodol. 2015, 15, 35. [CrossRef] [PubMed] 
22. Jayaraj, R.; Kumarasamy, C.; Madhav, M.R.; Pandey, V.; Sabarimurugan, S.; Ramesh, N.; Gothandam, K.M.; Baxi, S. Comment on "Systematic Review and Meta-Analysis of Diagnostic Accuracy of miRNAs in Patients with Pancreatic Cancer". Dis. Mark. 2018, 2018, 6904569. [CrossRef] [PubMed]

23. Jayaraj, R.; Kumarasamy, C. Comment on 'Prognostic biomarkers for oral tongue squamous cell carcinoma: A systematic review and meta-analysis'. Br. J. Cancer 2018, 118, e11. [CrossRef] [PubMed]

24. Jayaraj, R.; Kumarasamy, C.; Sabarimurugan, S.; Baxi, S. Letter to the Editor in response to the article. "The epidemiology of oral human papillomavirus infection in healthy populations: A systematic review and meta-analysis". Oral Oncol. 2018, 84, 121-122. [CrossRef] [PubMed]

25. Jayaraj, R.; Kumarasamy, C.; Sabarimurugan, S.; Baxi, S. Commentary: Blood-Derived microRNAs for Pancreatic Cancer Diagnosis: A Narrative Review and Meta-Analysis. Front. Physiol. 2018, 9, 1896. [CrossRef] [PubMed]

26. Jayaraj, R.; Kumarasamy, C. Conceptual interpretation of analysing and reporting of results on systematic review and meta-analysis of optimal extent of lateral neck dissection for well-differentiated thyroid carcinoma with metastatic lateral neck lymph nodes. Oral Oncol. 2019, 89, 153. [CrossRef] [PubMed]

27. Jayaraj, R.; Kumarasamy, C.J.A.R. Conceptual, statistical and clinical interpretation of results from a systematic review and meta-analysis of prevalence of cervical HPV infection in women with SLE. Autoimmun. Rev. 2019, 18, 433-434. [CrossRef] [PubMed]

28. Jayaraj, R.; Kumarasamy, C.; Gothandam, K.M. Letter to the editor "Prognostic value of microRNAs in colorectal cancer: A meta-analysis". Cancer Manag. Res 2018, 10, 3501-3503. [CrossRef] [PubMed]

29. Jayaraj, R.; Kumarasamy, C. Letter to the Editor about the Article: "Performance of different imaging techniques in the diagnosis of head and neck cancer mandibular invasion: A systematic review and meta-analysis". J. Oral Oncol. 2018, 89, 159-160. [CrossRef] [PubMed]

30. Kumarasamy, C.; Devi, A.; Jayaraj, R. Prognostic value of microRNAs in head and neck cancers: A systematic review and meta-analysis protocol. Syst. Rev. 2018, 7, 150. [CrossRef] [PubMed]

31. Jayaraj, R.; Kumarasamy, C. Comment on, "Survival for HPV-positive oropharyngeal squamous cell carcinoma with surgical versus non-surgical treatment approach: A systematic review and meta-analysis". J. Oral Oncol. 2018, 90, 137-138. [CrossRef] [PubMed]

32. Jayaraj, R.; Kumarasamy, C. Systematic review and meta-analysis of cancer studies evaluating diagnostic test accuracy and prognostic values: Approaches to improve clinical interpretation of results. Cancer Manag. Res. 2018, 10, 4669-4670. [CrossRef]

33. Jayaraj, R.; Kumarasamy, C.; Ramalingam, S.; Devi, A. Systematic review and meta-analysis of risk-reductive dental strategies for medication related osteonecrosis of the jaw among cancer patients: Approaches and strategies. Oral Oncol. 2018, 86, 312-313. [CrossRef]

34. Sabarimurugan, S.; Kumarasamy, C.; Baxi, S.; Devi, A.; Jayaraj, R. Systematic review and meta-analysis of prognostic microRNA biomarkers for survival outcome in nasopharyngeal carcinoma. PLoS ONE 2019, 14, e0209760. [CrossRef]

35. Sabarimurugan, S.; Madurantakam Royam, M.; Das, A.; Das, S.; Gothandam, K.M.; Jayaraj, R. Systematic Review and Meta-analysis of the Prognostic Significance of miRNAs in Melanoma Patients. Mol. Diagn. 2018, 22, 653-669. [CrossRef]

36. Jayaraj, R.; Kumarasamy, C.; Piedrafita, D. Systematic review and meta-analysis protocol for Fasciola DNA vaccines. Online J. Vet. Res. 2018, 22, 517.

37. Egger, M.; Smith, G.D.; Schneider, M.; Minder, C. Bias in meta-analysis detected by a simple, graphical test. BMJ 1997, 315, 629-634. [CrossRef] [PubMed]

38. Orwin, R.G. A fail-safe N for effect size in meta-analysis. J. Educ. Stat. 1983, 8, 157-159. [CrossRef]

39. Duval, S.; Tweedie, R. Trim and fill: A simple funnel-plot-based method of testing and adjusting for publication bias in meta-analysis. Biometrics 2000, 56, 455-463. [CrossRef]

40. Begg, C.B.; Mazumdar, M. Operating characteristics of a rank correlation test for publication bias. Biometrics 1994, 50, 1088-1101. [CrossRef]

41. De Carvalho, A.C.; Scapulatempo-Neto, C.; Maia, D.C.C.; Evangelista, A.F.; Morini, M.A.; Carvalho, A.L.; Vettore, A.L. Accuracy of microRNAs as markers for the detection of neck lymph node metastases in patients with head and neck squamous cell carcinoma. BMC Med. 2015, 13, 108. 
42. Hou, B.; Ishinaga, H.; Midorikawa, K.; Shah, S.A.; Nakamura, S.; Hiraku, Y.; Oikawa, S.; Murata, M.; Takeuchi, K. Circulating microRNAs as novel prognosis biomarkers for head and neck squamous cell carcinoma. Cancer Biol. Ther. 2015, 16, 1042-1046. [CrossRef]

43. Maia, D.; de Carvalho, A.C.; Horst, M.A.; Carvalho, A.L.; Scapulatempo-Neto, C.; Vettore, A.L. Expression of miR-296-5p as predictive marker for radiotherapy resistance in early-stage laryngeal carcinoma. J. Transl. Med. 2015, 13, 262. [CrossRef]

44. Hudcova, K.; Raudenska, M.; Gumulec, J.; Binkova, H.; Horakova, Z.; Kostrica, R.; Babula, P.; Adam, V.; Masarik, M. Expression profiles of miR-29c, miR-200b and miR-375 in tumour and tumour-adjacent tissues of head and neck cancers. Tumor Biol. 2016, 37, 12627-12633. [CrossRef]

45. Wang, H.; Zhang, G.; Wu, Z.; Lu, B.; Yuan, D.; Li, X.; Lu, Z. MicoRNA-451 is a novel tumor suppressor via targeting c-myc in head and neck squamous cell carcinomas. J. Cancer Res. Ther. 2015, 11, 216.

46. Arantes, L.M.R.B.; Laus, A.C.; Melendez, M.E.; de Carvalho, A.C.; Sorroche, B.P.; De Marchi, P.R.M.; Evangelista, A.F.; Scapulatempo-Neto, C.; de Souza Viana, L.; Carvalho, A.L. MiR-21 as prognostic biomarker in head and neck squamous cell carcinoma patients undergoing an organ preservation protocol. Oncotarget 2017, 8, 9911. [CrossRef] [PubMed]

47. Xu, H.; Yang, Y.; Zhao, H.; Yang, X.; Luo, Y.; Ren, Y.; Liu, W.; Li, N. Serum miR-483-5p: A novel diagnostic and prognostic biomarker for patients with oral squamous cell carcinoma. Tumor Biol. 2016, 37, 447-453. [CrossRef] [PubMed]

48. Li, G.; Ren, S.; Su, Z.; Liu, C.; Deng, T.; Huang, D.; Tian, Y.; Qiu, Y.; Liu, Y. Increased expression of miR-93 is associated with poor prognosis in head and neck squamous cell carcinoma. Tumor Biol. 2015, 36, 3949-3956. [CrossRef] [PubMed]

49. Hu, A.; Huang, J.-J.; Xu, W.-H.; Jin, X.-J.; Li, J.-P.; Tang, Y.-J.; Huang, X.-F.; Cui, H.-J.; Sun, G.-B. miR-21 and miR-375 microRNAs as candidate diagnostic biomarkers in squamous cell carcinoma of the larynx: Association with patient survival. Am. J. Transl. Res. 2014, 6, 604. [PubMed]

50. Hedbäck, N.; Jensen, D.H.; Specht, L.; Fiehn, A.-M.K.; Therkildsen, M.H.; Friis-Hansen, L.; Dabelsteen, E.; von Buchwald, C. MiR-21 expression in the tumor stroma of oral squamous cell carcinoma: An independent biomarker of disease free survival. PLoS ONE 2014, 9, e95193. [CrossRef] [PubMed]

51. Sun, L.; Liu, B.; Lin, Z.; Yao, Y.; Chen, Y.; Li, Y.; Chen, J.; Yu, D.; Tang, Z.; Wang, B. MiR-320a acts as a prognostic factor and Inhibits metastasis of salivary adenoid cystic carcinoma by targeting ITGB3. Mol. Cancer 2015, 14, 96. [CrossRef]

52. Saito, K.; Inagaki, K.; Kamimoto, T.; Ito, Y.; Sugita, T.; Nakajo, S.; Hirasawa, A.; Iwamaru, A.; Ishikura, T.; Hanaoka, H. MicroRNA-196a is a putative diagnostic biomarker and therapeutic target for laryngeal cancer. PLOS ONE 2013, 8, e71480. [CrossRef]

53. Li, J.; Huang, H.; Sun, L.; Yang, M.; Pan, C.; Chen, W.; Wu, D.; Lin, Z.; Zeng, C.; Yao, Y. MiR-21 indicates poor prognosis in tongue squamous cell carcinomas as an apoptosis inhibitor. Clin. Cancer Res. 2009, 15, 3998-4008. [CrossRef]

54. Liu, N.; Chen, N.-Y.; Cui, R.-X.; Li, W.-F.; Li, Y.; Wei, R.-R.; Zhang, M.-Y.; Sun, Y.; Huang, B.-J.; Chen, M. Prognostic value of a microRNA signature in nasopharyngeal carcinoma: A microRNA expression analysis. Lancet Oncol. 2012, 13, 633-641. [CrossRef]

55. Summerer, I.; Niyazi, M.; Unger, K.; Pitea, A.; Zangen, V.; Hess, J.; Atkinson, M.J.; Belka, C.; Moertl, S.; Zitzelsberger, H. Changes in circulating microRNAs after radiochemotherapy in head and neck cancer patients. Radiat. Oncol. 2013, 8, 296. [CrossRef] [PubMed]

56. Suh, Y.E.; Raulf, N.; Gäken, J.; Lawler, K.; Urbano, T.G.; Bullenkamp, J.; Gobeil, S.; Huot, J.; Odell, E.; Tavassoli, M. MicroRNA-196a promotes an oncogenic effect in head and neck cancer cells by suppressing annexin A1 and enhancing radioresistance. Int. J. Cancer 2015, 137, 1021-1034. [CrossRef]

57. Ogawa, T.; Saiki, Y.; Shiga, K.; Chen, N.; Fukushige, S.; Sunamura, M.; Nagase, H.; Hashimoto, S.; Matsuura, K.; Saijo, S. mi R-34a is downregulated in cis-diamminedichloroplatinum treated sinonasal squamous cell carcinoma patients with poor prognosis. Cancer Sci. 2012, 103, 1737-1743. [CrossRef]

58. Avissar, M.; McClean, M.D.; Kelsey, K.T.; Marsit, C.J. MicroRNA expression in head and neck cancer associates with alcohol consumption and survival. Carcinogenesis 2009, 30, 2059-2063. [CrossRef] [PubMed]

59. Re, M.; Çeka, A.; Rubini, C.; Ferrante, L.; Zizzi, A.; Gioacchini, F.M.; Tulli, M.; Spazzafumo, L.; Sellari-Franceschini, S.; Procopio, A.D. Micro RNA-34c-5p is related to recurrence in laryngeal squamous cell carcinoma. Laryngoscope 2015, 125, E306-E312. [CrossRef] 
60. Sun, Q.; Zhang, J.; Cao, W.; Wang, X.; Xu, Q.; Yan, M.; Wu, X.; Chen, W. Dysregulated miR-363 affects head and neck cancer invasion and metastasis by targeting podoplanin. Int. J. Biochem. Cell Biol. 2013, 45, 513-520. [CrossRef] [PubMed]

61. Tian, L.; Li, M.; Ge, J.; Guo, Y.; Sun, Y.; Liu, M.; Xiao, H. MiR-203 is downregulated in laryngeal squamous cell carcinoma and can suppress proliferation and induce apoptosis of tumours. Tumour Biol. J. Int. Soc. Oncodev. Biol. Med. 2014, 35, 5953-5963. [CrossRef]

62. Chang, C.-C.; Yang, Y.-J.; Li, Y.-J.; Chen, S.-T.; Lin, B.-R.; Wu, T.-S.; Lin, S.-K.; Kuo, M.Y.-P.; Tan, C.-T. MicroRNA-17/20a functions to inhibit cell migration and can be used a prognostic marker in oral squamous cell carcinoma. Oral Oncol. 2013, 49, 923-931. [CrossRef]

63. Gee, H.E.; Camps, C.; Buffa, F.M.; Patiar, S.; Winter, S.C.; Betts, G.; Homer, J.; Corbridge, R.; Cox, G.; West, C.M.; et al. hsa-mir-210 is a marker of tumor hypoxia and a prognostic factor in head and neck cancer. Cancer 2010, 116, 2148-2158. [CrossRef] [PubMed]

64. Lenarduzzi, M.; Hui, A.B.; Alajez, N.M.; Shi, W.; Williams, J.; Yue, S.; O’Sullivan, B.; Liu, F.F. MicroRNA-193b enhances tumor progression via down regulation of neurofibromin 1. PLoS ONE 2013, 8, e53765. [CrossRef]

65. Childs, G.; Fazzari, M.; Kung, G.; Kawachi, N.; Brandwein-Gensler, M.; McLemore, M.; Chen, Q.; Burk, R.D.; Smith, R.V.; Prystowsky, M.B.; et al. Low-level expression of microRNAs let-7d and miR-205 are prognostic markers of head and neck squamous cell carcinoma. Am. J. Pathol. 2009, 174, 736-745. [CrossRef] [PubMed]

66. Shen, Z.; Zhan, G.; Ye, D.; Ren, Y.; Cheng, L.; Wu, Z.; Guo, J. MicroRNA-34a affects the occurrence of laryngeal squamous cell carcinoma by targeting the antiapoptotic gene survivin. Med. Oncol. 2012, 29, 2473-2480. [CrossRef] [PubMed]

67. Luo, Z.; Dai, Y.; Zhang, L.; Jiang, C.; Li, Z.; Yang, J.; McCarthy, J.B.; She, X.; Zhang, W.; Ma, J.; et al. miR-18a promotes malignant progression by impairing microRNA biogenesis in nasopharyngeal carcinoma. Carcinogenesis 2013, 34, 415-425. [CrossRef]

68. Jung, H.M.; Phillips, B.L.; Patel, R.S.; Cohen, D.M.; Jakymiw, A.; Kong, W.W.; Cheng, J.Q.; Chan, E.K. Keratinization-associated $\mathrm{miR}-7$ and $\mathrm{miR}-21$ regulate tumor suppressor reversion-inducing cysteine-rich protein with kazal motifs (RECK) in oral cancer. J. Biol. Chem. 2012, 287, 29261-29272. [CrossRef]

69. Sasahira, T.; Kurihara, M.; Bhawal, U.K.; Ueda, N.; Shimomoto, T.; Yamamoto, K.; Kirita, T.; Kuniyasu, H. Downregulation of miR-126 induces angiogenesis and lymphangiogenesis by activation of VEGF-A in oral cancer. Br. J. Cancer 2012, 107, 700-706. [CrossRef] [PubMed]

70. Liu, C.J.; Shen, W.G.; Peng, S.Y.; Cheng, H.W.; Kao, S.Y.; Lin, S.C.; Chang, K.W. miR-134 induces oncogenicity and metastasis in head and neck carcinoma through targeting WWOX gene. Int. J. Cancer 2014, 134, 811-821. [CrossRef] [PubMed]

71. Shi, L.J.; Zhang, C.Y.; Zhou, Z.T.; Ma, J.Y.; Liu, Y.; Bao, Z.X.; Jiang, W.W. MicroRNA-155 in oral squamous cell carcinoma: Overexpression, localization, and prognostic potential. Head Neck 2015, 37, 970-976. [CrossRef]

72. Harris, T.; Jimenez, L.; Kawachi, N.; Fan, J.-B.; Chen, J.; Belbin, T.; Ramnauth, A.; Loudig, O.; Keller, C.E.; Smith, R.; et al. Low-level expression of miR-375 correlates with poor outcome and metastasis while altering the invasive properties of head and neck squamous cell carcinomas. Am. J. Pathol. 2012, 180, 917-928. [CrossRef]

73. Huang, W.C.; Chan, S.H.; Jang, T.H.; Chang, J.W.; Ko, Y.C.; Yen, T.C.; Chiang, S.L.; Chiang, W.F.; Shieh, T.Y.; Liao, C.T.; et al. miRNA-491-5p and GIT1 serve as modulators and biomarkers for oral squamous cell carcinoma invasion and metastasis. Cancer Res. 2014, 74, 751-764. [CrossRef]

74. Shiiba, M.; Shinozuka, K.; Saito, K.; Fushimi, K.; Kasamatsu, A.; Ogawara, K.; Uzawa, K.; Ito, H.; Takiguchi, Y.; Tanzawa, H. MicroRNA-125b regulates proliferation and radioresistance of oral squamous cell carcinoma. Br. J. Cancer 2013, 108, 1817-1821. [CrossRef]

75. Zeng, X.; Xiang, J.; Wu, M.; Xiong, W.; Tang, H.; Deng, M.; Li, X.; Liao, Q.; Su, B.; Luo, Z.; et al. Circulating miR-17, miR-20a, miR-29c, and miR-223 combined as non-invasive biomarkers in nasopharyngeal carcinoma. PLoS ONE 2012, 7, e46367. [CrossRef] [PubMed]

76. Liu, N.; Jiang, N.; Guo, R.; Jiang, W.; He, Q.M.; Xu, Y.F.; Li, Y.Q.; Tang, L.L.; Mao, Y.P.; Sun, Y.; et al. MiR-451 inhibits cell growth and invasion by targeting MIF and is associated with survival in nasopharyngeal carcinoma. Mol. Cancer 2013, 12, 123. [CrossRef] [PubMed]

77. Yang, C.C.; Hung, P.S.; Wang, P.W.; Liu, C.J.; Chu, T.H.; Cheng, H.W.; Lin, S.C. miR-181 as a putative biomarker for lymph-node metastasis of oral squamous cell carcinoma. J. Oral Pathol. Med. 2011, 40, $397-404$. [CrossRef] [PubMed] 
78. Wu, T.-Y.; Zhang, T.-H.; Qu, L.-M.; Feng, J.-P.; Tian, L.-L.; Zhang, B.-H.; Li, D.-D.; Sun, Y.-N.; Liu, M. MiR-19a is correlated with prognosis and apoptosis of laryngeal squamous cell carcinoma by regulating TIMP-2 expression. Int. J. Clin. Exp. Pathol. 2013, 7, 56-63. [PubMed]

79. Peng, S.C.; Liao, C.T.; Peng, C.H.; Cheng, A.J.; Chen, S.J.; Huang, C.G.; Hsieh, W.P.; Yen, T.C. MicroRNAs MiR-218, MiR-125b, and Let-7g predict prognosis in patients with oral cavity squamous cell carcinoma. PLoS ONE 2014, 9, e102403. [CrossRef] [PubMed]

80. Gonzalez-Arriagada, W.A.; Olivero, P.; Rodriguez, B.; Lozano-Burgos, C.; de Oliveira, C.E.; Coletta, R.D. Clinicopathological significance of miR-26, miR-107, miR-125b, and miR-203 in head and neck carcinomas. Oral Dis. 2018, 24, 930-939. [CrossRef] [PubMed]

81. El Baroudi, M.; Machiels, J.P.; Schmitz, S. Expression of SESN1, UHRF1BP1, and miR-377-3p as prognostic markers in mutated TP53 squamous cell carcinoma of the head and neck. Cancer Biol. 2017, 18, 775-782. [CrossRef] [PubMed]

82. Berania, I.; Cardin, G.B.; Clement, I.; Guertin, L.; Ayad, T.; Bissada, E.; Nguyen-Tan, P.F.; Filion, E.; Guilmette, J.; Gologan, O.; et al. Four PTEN-targeting co-expressed miRNAs and ACTN4-targeting miR-548b are independent prognostic biomarkers in human squamous cell carcinoma of the oral tongue. Int. J. Cancer 2017, 141, 2318-2328. [CrossRef] [PubMed]

83. He, F.Y.; Liu, H.J.; Guo, Q.; Sheng, J.L. Reduced miR-300 expression predicts poor prognosis in patients with laryngeal squamous cell carcinoma. Eur. Rev. Med. Pharmacol. Sci. 2017, 21, 760-764.

84. Hess, A.K.; Muer, A.; Mairinger, F.D.; Weichert, W.; Stenzinger, A.; Hummel, M.; Budach, V.; Tinhofer, I. MiR-200b and miR-155 as predictive biomarkers for the efficacy of chemoradiation in locally advanced head and neck squamous cell carcinoma. Eur. J. Cancer 2017, 77, 3-12. [CrossRef]

85. Jiang, C.; Wang, H.; Zhou, L.; Jiang, T.; Xu, Y.; Xia, L. MicroRNA-212 inhibits the metastasis of nasopharyngeal carcinoma by targeting SOX4. Oncol. Rep. 2017, 38, 82-88. [CrossRef] [PubMed]

86. Liu, N.; Zhou, Q.; Qi, Y.H.; Wang, H.; Yang, L.; Fan, Q.Y. Effects of long non-coding RNA H19 and microRNA let7a expression on thyroid cancer prognosis. Exp. Mol. Pathol. 2017, 103, 71-77. [CrossRef] [PubMed]

87. Re, M.; Magliulo, G.; Gioacchini, F.M.; Bajraktari, A.; Bertini, A.; Ceka, A.; Rubini, C.; Ferrante, L.; Procopio, A.D.; Olivieri, F. Expression Levels and Clinical Significance of miR-21-5p, miR-let-7a, and miR-34c-5p in Laryngeal Squamous Cell Carcinoma. Biomed Res. Int. 2017, 2017, 3921258. [CrossRef] [PubMed]

88. Romeo, P.; Colombo, C.; Granata, R.; Calareso, G.; Gualeni, A.V.; Dugo, M.; De Cecco, L.; Rizzetti, M.G.; Zanframundo, A.; Aiello, A.; et al. Circulating miR-375 as a novel prognostic marker for metastatic medullary thyroid cancer patients. Endocr. Relat. Cancer 2018, 25, 217-231. [CrossRef] [PubMed]

89. Wilkins, O.M.; Titus, A.J.; Salas, L.A.; Gui, J.; Eliot, M.; Butler, R.A.; Sturgis, E.M.; Li, G.; Kelsey, K.T.; Christensen, B.C. MicroRNA-Related Genetic Variants Associated with Survival of Head and Neck Squamous Cell Carcinoma. Cancer Epidemiol. Biomark. Prev. 2019, 28, 127-136. [CrossRef] [PubMed]

90. Yu, E.H.; Tu, H.F.; Wu, C.H.; Yang, C.C.; Chang, K.W. MicroRNA-21 promotes perineural invasion and impacts survival in patients with oral carcinoma. J. Chin. Med. Assoc. JCMA 2017, 80, 383-388. [CrossRef] [PubMed]

91. Madurantakam, R.M.; Kumarasamy, C.; Baxi, S.; Gupta, A.; Ramesh, N.; Kodiveri, M.G.; Jayaraj, R. Current Evidence on miRNAs as Potential Theranostic Markers for Detecting Chemoresistance in Colorectal Cancer: A Systematic Review and Meta-Analysis of Preclinical and Clinical Studies. Mol. Diagn. Ther. 2019, 23, 65-82. [CrossRef]

92. Madhav, M.R.; Nayagam, S.G.; Biyani, K.; Pandey, V.; Kamal, D.G.; Sabarimurugan, S.; Ramesh, N.; Gothandam, K.M.; Jayaraj, R. Epidemiologic analysis of breast cancer incidence, prevalence, and mortality in India: Protocol for a systematic review and meta-analyses. Medicine 2018, 97, e13680. [CrossRef]

93. Poddar, A.; Aranha, R.R.; Muthukaliannan, G.K.; Nachimuthu, R.; Jayaraj, R. Head and neck cancer risk factors in India: Protocol for systematic review and meta-analysis. BMJ Open 2018, 8, e020014. [CrossRef]

(C) 2019 by the authors. Licensee MDPI, Basel, Switzerland. This article is an open access article distributed under the terms and conditions of the Creative Commons Attribution (CC BY) license (http://creativecommons.org/licenses/by/4.0/). 